\title{
N-3 Polyunsaturated Fatty Acids and Inflammation in Obesity: Local Effect and Systemic Benefit
}

\author{
Yue Wang and Feiruo Huang \\ Department of Animal Nutrition and Feed Science, College of Animal Science and Technology, \\ Huazhong Agricultural University, Wuhan 430070, China \\ Correspondence should be addressed to Feiruo Huang; huangfeiruo@mail.hzau.edu.cn
}

Received 25 September 2014; Accepted 11 January 2015

Academic Editor: Karsten Weylandt

Copyright (C) 2015 Y. Wang and F. Huang. This is an open access article distributed under the Creative Commons Attribution License, which permits unrestricted use, distribution, and reproduction in any medium, provided the original work is properly cited.

\begin{abstract}
Overwhelming consensus emerges among countless evidences that obesity is characterized by a chronic low-grade inflammation in the adipose tissue (AT), which subsequently develops into a systemic inflammatory state contributing to obesity-associated diseases. N-3 Polyunsaturated fatty acids (n-3 PUFA), known as important modulators participating in inflammatory process, turn out to be an effective mitigating strategy dealing with local and systemic inflammation observed in obesity. Some of the effects of n-3 PUFA are brought about by regulation of gene expression through interacting with nuclear receptors and transcription factors; other effects are elicited by modulation of the amount and type of mediator derived from PUFAs. The metabolic effects of n-3 PUFA mainly result from their interactions with several organ systems, not limited to AT. Notably, the attenuation of inflammation in hard-hit AT, in turn, contributes to reducing circulating concentrations of proinflammatory cytokines and detrimental metabolic derivatives, which is beneficial for the function of other involved organs. The present review highlights a bridging mechanism between n-3 PUFA-mediated inflammation relief in AT and systemic benefits.
\end{abstract}

\section{Introduction}

There are mounting evidences demonstrating that obesity and associated disorders pose a daunting threat on global public health problem, given their morbidity and mortality. Obesity is associated with a chronic low-grade inflammatory response characterized by abnormal cytokine production, increased acute phase reactants, and activation of inflammatory signaling pathways $[1,2]$. It is specifically the excessive accumulation of body fat in AT that initiates local inflammation and later systemic response [3]. AT is more like an important endocrine and immune organ, secreting a considerable variety of adipokines, including inflammatory mediators [3, 4]. Increased circulating concentration of these cytokines is triggered by obesity and proven associated with pathogenesis of metabolic syndrome $[1,5]$. That partly explains why obese individual is vulnerable to serious complications, ranging from diabetes to cardiovascular disease. AT inflammation is never considered as a mere local reaction. Instead, locally inflamed AT exerts profound influences on other organs and systems.
The anti-inflammatory properties of n-3 PUFA are not novel concepts, and the benefits of dietary supplementation with n-3 PUFA are well documented in several inflammatory and autoimmune diseases, including obesity $[6,7]$. Under the condition of obesity, catabasis of inflammation manifestation mediated by n-3 PUFA is never restricted to AT. In parallel, it indeed benefits the improvement of other metabolic sites. According to our observation, even during normal physiological processes, n-3 PUFA suppresses the expression of proinflammatory cytokines and decreases the circulatory TNF- $\alpha$ concentration [8]. It is conceivable that the anti-inflammatory potential of n-3 PUFA might be stretched under the inflammatory status. However, it seems reasonable to suppose that n-3 PUFA may mediate some of its beneficial effects on whole-body homeostasis by resetting the function of AT. Since the peroxisome proliferator-activated receptorgamma (PPAR $\gamma$ ) functions as an effector of adipocytederived T helper 2 (Th2) cytokines [9] whose activation is required for the circulating monocytes differentiation into M2 macrophages and anti-inflammatory gene transcription, as discussed later in this review, typically, PPAR $\gamma$ might 
function as communicator integrating inflammation relief in AT into systemic benefits. The emphasis of present review is upon benefits from n-3 PUFA supplementation in models of chronic inflammatory conditions companied with obesity. On a global level, the potential adipocentric beneficial effects are expended into systemic effects. Given its desirable antiinflammatory effect, dietary manipulation with n-3 PUFA may therefore offer a logical strategy for preventing or treating obesity and obesity-induced complications.

\section{Adipose Tissue Inflammation in Obesity}

Interestingly, inflammation emerging in the context of obesity seems to be triggered and to reside predominantly, in the AT [10], although other organs actively involved in metabolism also inevitably suffer from a chronic low-grade inflammation during the development of the diseases. More than a notable characteristic of obesity, AT inflammation is considered as causative factors connecting obesity with its metabolic complications [3, 11-13].

In addition to matrix of extracellular proteins, adipocytes are surrounded by a wide variety of cells, including endothelium, fibroblasts, preadipocytes, and immune cells [14]. In contrast to previous understanding, adipocytes are increasingly recognized as an integrator of various physiological pathways rather than a passive energy storage depot with a droplet which is completely out of the proportion [15]. This recognition begins with the observation that adipocyte is a significant source of endogenous tumor necrosis factor $\alpha$ (TNF- $\alpha$ ) at which secretion is substantially stimulated by obesity $[10,16]$. Adipocytes are equipped with the ability to secrete a large number of adipokines (interleukin-6 (IL-6), interleukin-1 (IL-1), chemokine monocyte chemotactic protein, leptin, adiponectin, resistin, etc.) [15]. Following adipocytes, resident immune cells constitute the second largest AT cellular component [3]. Obesity-induced infiltration of immune cells into AT leads to increased synthesis and subsequent secretion of proinflammatory factors into circulation [17].

Obesity is featured by progressive infiltration of immune cells into AT. Adipocytes are studied with increasing intensity, while some pursuit concentrates on the possibility that the cellular source of these inflammatory changes derives not only from adipocytes. Actually, since the majority of cytokines produced in obese AT are adipose tissue macrophage (ATM) derived, it is speculated that recruitment and proinflammatory activation of ATM are required for the development of obesity-associated complication [18, 19]. Histologically, there is evidence of significant infiltration of macrophages into white adipose tissue (WAT) of obese mice, which well supports earlier microarray analysis demonstrating that gene product expressed in macrophage is markedly increased in obese (ob/ob) AT [20-22] and unequivocally explains previous discoveries that macrophage accumulation is positively correlated with body mass index (BMI) and adipocyte size $[14,21]$. With the deterioration of obesity, macrophages recruit in the AT, sometimes contributing as much as half of the cellularity [21]. The state of chronic low-grade inflammation in WAT is powerfully augmented through the infiltration of macrophages [23]. Instead, fat reduction leads to a dramatic decrease in number and modified distribution of macrophages together with decreased expression of inflammatory markers [22]. Not all ATM are programmed for proinflammation, since even, for lean mice, moderate quantity of ATM is present in the context of low or undetectable inflammatory signals [21]. Diet-induced obesity leads to a shift in the activation state of ATM from an M2-polarized state in lean animals to a proinflammatory M1 polarization state [24]. The mechanism responsible for this phenotypic switch of macrophage polarization remains unclear. It is speculated that dietary n-3 PUFA servers as the monitor switch, which will be discussed in following context. It is worthwhile to mention that macrophage, overwhelmingly localized to necrotic adipocytes, is the predominant or significant source of proinflammatory adipokines in WAT [25]. Adipocyte death is one of the putative mechanisms explaining the initiation of macrophage infiltration into adipose [26].

In addition to macrophages infiltration, adipocyte hypertrophy and hyperplasia are followed by enhanced angiogenesis and extracellular matrix (ECM) overproduction. The protein composition and dynamics of ECM are critical for physiologic role of the AT [27]. Additionally, an emerging view is that adipocytes hypertrophy sets obstacle for sufficient oxygen supply to the cells, which creates a state of hypoxia followed by apoptosis of some cellular components $[28,29]$, once physical limit to adipocyte growth hardly copes with increased volume. Virtually, if disproportionate accumulation of ECM does not allow an adequate expansion of adipocytes, adipocytes are more susceptible to necrosis [30]. Presumably, as a process pathologically accelerated in obesity, unhealthy AT remodeling, not AT expansion, may be the root of the attraction of macrophages and final inflammation, at least necrosis adipocytes mainly caused by nutrition and oxygen deprivation are unignorable stimulus that drives immune cells infiltration as discussed before. More important, in spite of an enlarged fat mass, well controlled healthy AT expansions do not exhibit pathological changes and metabolic disorders [26].

Another marked feature of obesity is the dramatic upregulation of Inflammation and macrophage-specific genes in AT [1]. Earlier microarray performed in AT from wild-type and $o b / o b$ mice [20] and subsequent research concerning the treatment with PPAR $\gamma$ ligand in Zucker diabetic fatty (ZDF) rats [31] both disclose the notable regulation of inflammatory genes in AT during obesity development. In addition, extensive transcriptional profiling studies using multiple tissues taken from mice with genetic or diet-induced obesity indicate the majority of gene regulated in obesity comprises macrophage and inflammatory genes [1]. Similar conclusion is observed in the WAT of mice suffering from varying degrees of obesity [21].

Although macrophage invasion into visceral adipose tissue (VAT) is regarded as a dominant driving force leading to AT inflammation, there has also been a resurgence of interest into a unique population of VAT-resident regulatory $\mathrm{T}\left(\mathrm{T}_{\text {reg }}\right)$ cells characterized by the expression of forkhead box 
P3 (Foxp3). $\mathrm{T}_{\text {reg }}$ cells-mediated suppression turns out to be an effective defense against aberrant or excessive immune responses [32]. $\mathrm{T}_{\text {reg }}$ cells are abundant in the VAT of normal but not obese individuals, suggesting that they are engaged in control of the inflammatory state of AT [33]. What is more, they have a different $\mathrm{T}$ cell receptor repertoire compared with $\mathrm{T}_{\text {reg }}$ cells residing in other tissues, which also indicates their novelty. Interestingly, VAT $\mathrm{T}_{\text {reg }}$ cells reduce strikingly and specifically in insulin-resistant models of obesity. Conversely, their expansion improves insulin sensitivity [33]. Loss-offunction and gain-of-function experiments further confirm their influence on the surrounding adipocytes, inflammatory state of AT, and insulin sensitivity, coupled with differentially synthesized cytokines [33]. It is likely that the shortage of VAT-resident $\mathrm{T}_{\text {reg }}$ cells offers the answer why obesityassociated inflammation can escape the powerful armamentarium of cells and molecular ready for curbing a runaway immune response.

Exposed to obesity-susceptive environment, complex events take place in AT in a defined order with a number of critical cell types participating in this process, as shown in Figure 1.

\section{Systemic Consequences in Response to Local Inflammation}

Elevated TNF- $\alpha$ expression in AT from rodent models of obesity was first proposed in 1993 [16]. Subsequently, the novel function of TNF- $\alpha$ is verified in different rodent obesity models as well as in obese humans [10, 34-36]. The absence of TNF- $\alpha$ results in significantly improved insulin sensitivity in both diet-induced and $o b / o b$ model of obesity [37]. In sharp contrast to elevated TNF- $\alpha$ expression in AT, circulating TNF- $\alpha$ concentrations in obesity are found unchanged or disproportionately increased [16, 38, 39]. Demonstration of elevated expression of transmembrane forms of TNF- $\alpha$ in obesity well confirms the spatial restriction of TNF- $\alpha$, suggesting the action of this cytokine is restricted to AT because of TNF- $\alpha$ retention on the cell surface [36]. Attempts to reverse insulin resistance with an injection of anti-TNF binding proteins finally fail [40,41], indirectly supporting the speculation that TNF- $\alpha$ functions locally at AT via a paracrine or autocrine fashion. However, it would be premature to conclude that AT inflammation is an isolated system.

TNF- $\alpha$ is able to amplify inflammatory response via activating other cytokine networks and proinflammatory pathways [42]. Apart from TNF- $\alpha$, there is a significant graded increase of proinflammatory cytokines, such as IL-6 as well as acute phase markers, which work in a coordinated manner to impact whole-body hemostasis. More direct and detailed discussions concerning the linkage between these cytokines and inflammation associated diseases are reported before [42]. Studies concerning the origins of the accumulated triacylglycerol (TAG) in the liver during the development of nonalcohol fatty liver disease clarify that the primary contributor to hepatic TAG is serum nonesterified fatty acid (NEFA) pool, most of which derived from AT fatty acid flux [43]. Enhanced release of fatty acid from hypertrophic fat cells results in lipotoxicity caused by accumulation of lipid in nonadipose tissues, contributing to systemic insulin resistance [44]. However, a recent discovery, contrary to previous demonstration, not only challenges former opinion by confirming downregulated rates of NEFA delivery from AT, but also demonstrates that the implicit reduction in AT fatty acid uptake goes beyond the downregulation of systemic NEFA release from AT in obesity [45]. No matter what mechanism dominates the excess fat deposition in nonadipose tissue, accretive fatty acid release originated from AT or impaired AT storage of ingested fat, the dysfunction, and destruction necessarily associated with ectopic fat depots cannot be too strongly emphasized. Ectopic fat depots with predominantly systemic effects include VAT, intrahepatic fat, and intramuscular fat, whereas pericardial (or the related epicardial or pericoronary fat), renal sinus fat, myocardial steatosis, and perivascular fat are postulated to have potential local effects [46].

By analogy to proinflammatory mediators and free fatty acid (FFA), several adipokines, especially leptin and adiponectin protecting peripheral tissues against the lipotoxic damage by promoting oxidation of fatty acids and sensitizing insulin actions, are also an integral part of AT-derived factors which bridge the physiology of AT and function of non-AT tissues [44]. Unfortunately, obesity is always accompanied with increased leptin and decreased adiponectin in serum [47], negatively associated with desirable metabolic parameters.

A direct relationship between ATM with other metabolic or nonmetabolic disarrangements suggests that ATM plays integrated role that goes beyond local AT inflammation [48], with emphasizing on the effects of polarization state of ATM on systemic inflammation and insulin action [49, 50]. The mechanism underlying this process remains deeper investigation. According to achieved evidences, it is clear that vastly increased production of proinflammatory mediators derived from M1 macrophages results in their entry into the circulation to cause dysfunction of actively metabolized tissue.

In conclusion, the label of endocrine organ reflects the systemic effects of AT. Excessive accumulation of surplus body fat lies at the core of all these problems and initiates the release of a number of proinflammatory cytokines from adipocytes as well as tissue-resident macrophages, followed by a rapid recruitment of monocytes from circulation to the AT. Infiltrating cells deteriorate the state of inflammation by representing an additional source of proinflammatory cytokines, leading to disruption of normal homeostatic control of metabolism locally and systemically via endocrine or paracrine effects. In addition to dysregulation of secretory functions, impairment of storage function results in excessive release of free fatty acids and ectopic deposition in nonadipocyte cells, which dramatically worsens the situation [51, 52]. 

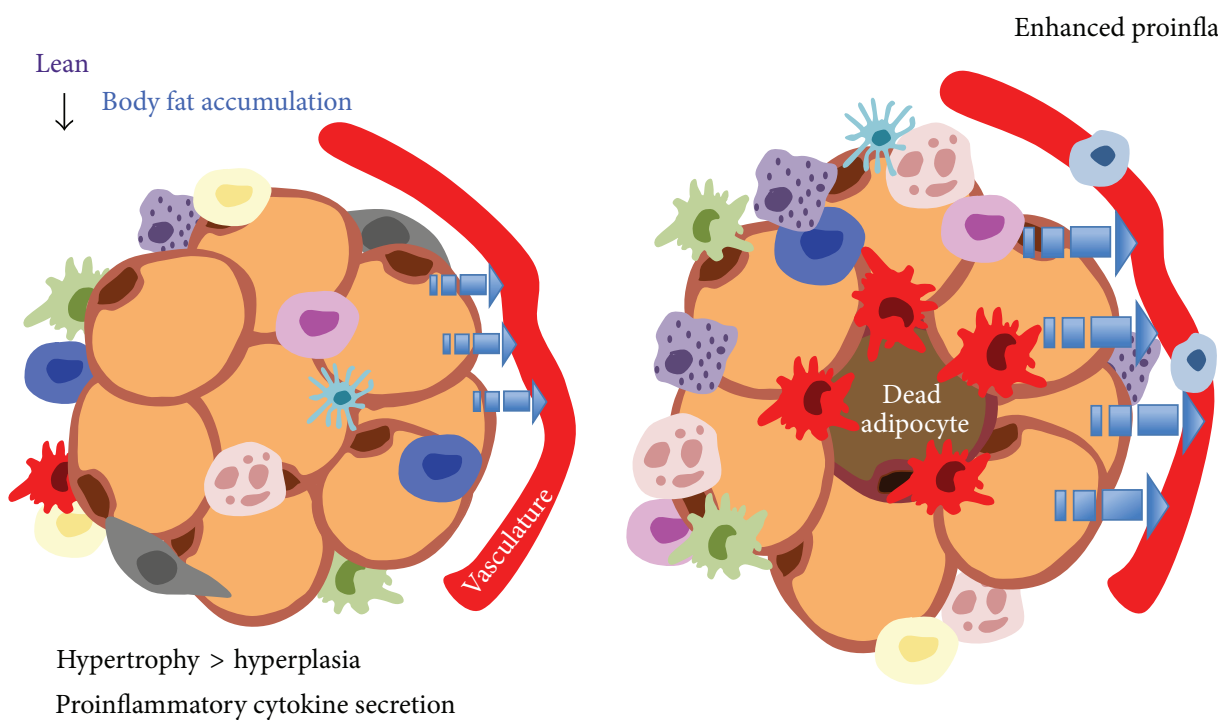

Hypertrophy > hyperplasia

Proinflammatory cytokine secretion

Expending $\longrightarrow$ Recruitment of immune cells $\longrightarrow$ Obese

atory mediator secretion

ECM overproduction

Adipocyte death

Hypoxia

Increased lipolysis

ER stress

\begin{tabular}{|l|}
\hline Adipokines alteration \\
\hline MCP-1 \\
\hline \hline IL-6 \\
\hline \hline TNF- $\alpha$ \\
\hline PAI-1 \\
\hline Angiotensin II \\
\hline Complement factors \\
\hline Leptin \\
\hline Adiponectin \\
\hline
\end{tabular}

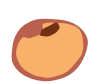

Adipocyte

Inn M1 macrophage

M2 macrophage
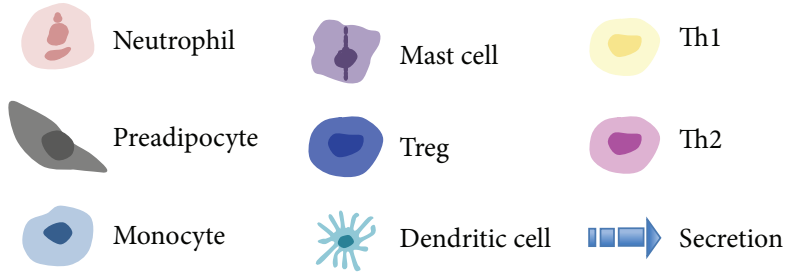

FIGURE 1: Alteration occurring in adipose tissue when it suffers from excessive TAG accumulation. In the face of chronic overnutrition, excessive adipose tissue expansion is initiated and dominated by adipocyte hypertrophy, whereas adipocyte number becomes fixed with obese individuals achieving a higher plateau. Activated adipocytes trigger production of proinflammatory mediators, together with resident immune cells, exerting functions in an endocrine and paracrine fashion. Infiltration of immune cells is secondary consequence followed by adipocyte activation. Mature adipocytes promote diapedesis of monocytes through microvascular endothelial cells, facilitating monocytederived macrophages accumulation. Progressive recruitment of immune cells underpins inflammation in AT by enhancing proinflammatory mediator secretion. Additionally, obese state pathologically accelerates AT remodeling featured by ECM overproduction, necrotic adipocyte, and hypoxia, along with dysregulation in fatty acid fluxes. Macrophages are predominantly localized around dead adipocytes. Sensibly, lean individuals exhibit higher ratios of M2:M1 macrophages, Th1:Th2 T cells. With the development of obesity, major shift in the above cell ratios favors a modest inflammation status (originality is inspired by previous review written by Evan D. Rosen and Bruce M. Spiegelman. Based on former illustration focusing on recruitment of immune cells, more detail and latest information are injected into the figure).

\section{N-3 PUFA-Mediated Prevention and Reversal of Metabolic Syndrome}

The structural feature, metabolic interconversion, and food source of n-3 PUFA are well demonstrated in previous literatures [53]. Numerous researches, in vivo or in vitro, confirm the positive effects of n-3 PUFA supplement on lipid and glucose metabolism, such as lower triacylglycerol concentration and higher high density lipoprotein (HDL) cholesterol levels in plasma, improved insulin sensitivity as well as reduced blood pressure $[54,55]$. Animal dietary intervention trials demonstrate that n-3 PUFA limits development of obesity and reduces cellularity of AT in the context of the diet rich in fat, with improvement of lipid and glucose metabolism [5658]. Importantly, n-3 PUFA administration alleviates highfat diet (HFD)/obesity-induced insulin resistance, which is equal to or greater than the effects of clinically used insulin sensitizing drug [59]. Clinical studies in humans also report that n-3 PUFA contributes to a significant decrease of body fat and improves glucose metabolism and plasma lipid profile simultaneously [60-62]. The division of scientific opinions focuses on the issue that n-3 PUFA consumption significantly reduces food intake [63], since some clearly observe less weight again in animals fed fish oil-based diets, an effect cannot be explained by less lower caloric intake [64]. The discrepancy likely comes from the level of energy intake and experimental design, since the weight gain of control animals varies distinctly between different studies, and the conclusion is based on the comparison with control treatments different in fatty acid content. Notably, the metabolic and molecular effects of different high-fat diets with varying fatty acid 
compositions are systemically compared. Unlike other highfat diets tested, n-3 PUFA dietary regimen appears to be the only treatment successful in fighting against high-fat induced metabolic deterioration associated with obesity [64].

As said before, inflammation is an inevitable feature in the development of obesity and contributes to obesity-related metabolic derangements. Conversely, ameliorating the lowgrade inflammation companied with obesity by n-3 PUFA benefits obesity and its sequelae via modulating adipokines secretion and improving insulin sensitivity [44].

Actually, the ratio of dietary n-6 to n-3 PUFA, rather than the absolute amount of $n-3$ PUFA, is important in determining the development of inflammatory response $[65,66]$. Linoleic acid and $\alpha$-linolenic acid (ALA) are the precursors responsible for the synthesis of n-6 and n-3 series, respectively. Despite different metabolites, the enzymes involved in their metabolism turn out to be the same, which means excessive intake of linoleic acid leads to reduced synthesis of docosahexaenoic acid (DHA) and eicosapentaenoic acid (EPA) because of competition for relevant enzymes. Increased ingestion of n-6 PUFA also inhibits EPA incorporation into neutrophil membranes and reduces the inhibition of production of inflammatory mediators [67, 68]. But in vivo, n-3 PUFA prevents the arachidonic acid- (AA-) induced increase in proinflammatory eicosanoids in fat cells [69]. Given the inefficiency of transformation from ALA to n-3 long-chain polyunsaturated fatty acid (LC-PUFA) $[70,71]$, increasing dietary consumption of EPA and DHA helps to reach the maximum beneficial effects. Besides that, precise difference exists between DHA and EPA and their precursor ALA, because longer carbohydrate chains seem more potent to exert stronger effects [7]. In most cases, it is active metabolites derived from n-3 PUFA, rather than themselves, that exerts anti-inflammatory effects.

\section{Anti-Inflammatory Effects of n-3 PUFA}

Clinical investigations of dietary supplementation with n3 PUFA indicate their beneficial impact on some certain diseases, especially those companied with inflammation [6]. Anti-inflammatory effects of n-3 PUFA are primarily demonstrated by two standpoints: inhibitory secretion of proinflammatory mediators $[72,73]$ and greatly reduced macrophage migration into AT [74]. On the other hand, as outlined in the later paragraphs, n-3 PUFA assists with body fat reduction by multiple mechanisms including prevention of adipocytes proliferation, increased fatty acid oxidation, and inhibited hepatic lipogenesis, which can be considered as an indirect way to exert its anti-inflammatory effects given the immune role played by AT. Last, incorporation of the n-3 PUFA into adipocyte membrane is also regarded as a metabolism for its favorable effect in AT. Alterations occurring in AT finally result in systemic benefits.

\subsection{Production of Proinflammatory and Anti-Inflammatory} Cytokines. Among these identified factors contributing to uncontrolled inflammation in obesity, special attention is given to bioactive lipid mediators derived from the cyclooxygenase and 5-lipoxygenase pathways, which convert the membrane-derived AA into potent proinflammatory eicosanoids (such as prostaglandin and leukotriene). Notably, active metabolites derived from PUFA indeed play indispensable roles in the development of inflammation [44]. In contrast to proinflammatory potential of eicosanoids derive from n-6 PUFA, eicosanoids derived from n-3 series are generally gifted in anti-inflammation [75]. A relatively small increase in n-3 LC-PUFA consumption significantly inhibits AA conversion to proinflammatory eicosanoids generated by the 5-lipoxygenase pathway of neutrophils, monocytes, and macrophages $[76,77]$. Thus, increase in dietary n-3 PUFA can shift the balance of the produced eicosanoids to a less inflammatory mixture, resulting from competitive inhibition of proinflammatory cytokines conversion.

In parallel, an arsenal of new lipid mediators is isolated and identified, suggesting that these novel families of anti-inflammatory mediators contrast with the earlier n3 PUFA-derived oxygenated products previously known as eicosanoids [78]. As we know, in most cases, inflammation is normally well regulated and followed by complete resolution that enables inflamed tissues to return to homeostasis due to the activation of negative feedback mechanisms, which means influx of specialized leukocytes induces mononuclear leukocytes recruitment to phagocytose apoptotic leukocytes and cells debris from inflamed site until the injurious stimulus is cleared and infiltrated leukocyte is removed [79]. Contrarily, chronic inflammation is featured by continual activation of the adaptive immune system that exacerbates the inflammatory response. Of special interests in this process are some previously ignored factors that signal the termination of inflammation. As endogenous local mediators, these bioactive substances derived from EPA and EHA during the resolution phase are termed protectins and resolvins, because specific members of these families are widely appreciated for their ability to stimulate and accelerate resolution [80, 81]. In addition to controlling the magnitude and duration of inflammation, resolvins and protectins also function as inflammation terminators facilitating removal of chemokines from the resolving milieu [78]. Emerging evidence demonstrates that resolvins and protectins exert a strict control towards the resolution process of AT inflammation and pave the way for monocyte migration and their differentiation into macrophages and even elicit macrophage polarization toward an M2-like phenotype [79, 82].

Besides the mediators derived from PUFA, it is confirmed that, for healthy volunteers, supplementation of n-3 PUFA suppresses the production of secreted proinflammatory mediators [83-85]. Indeed, monocytes pretreated with n3 PUFA significantly decrease proinflammatory production after lipopolysaccharide (LPS) stimulation [86-88]. Aligning with the emerging phenotype, a conceivable reduction in the expression of a number of inflammatory markers is achieved, in partial analogy to the situation with anti-inflammatory drugs treatment [63].

5.2. Alteration Occurring in Adipose Tissue. In addition to dietary PUFA-originated metabolites and n-3 PUFA-mediated 
cytokines secretion, recent studies implicate n-3 PUFA influence on the polarization and recruitment of macrophages [52]. ATM in lean individuals is of an anti-inflammatory phenotype but capable of excessive proinflammatory mediator production [89]. Incorporation of n-3 PUFA in diet completely prevents macrophage infiltration induced by high-fat diet [90], which is consistent with another research revealing dramatic reduction in ATM content, along with transformation from M1 to M2 polarization state [59]. Similar macrophage phenotypic switch considered as a benefit of n-3 PUFA is observed in Kupffer cells [91].

Undeniably, adipocyte is the other target through which n-3 PUFA prevents AT inflammation. One possible mechanism lies in the prevention of AT expanding and proliferation of adipocytes by n-3 PUFA. Antiadipogenic effect of n-3 PUFA significantly prevents fat accumulation by reducing cellularity of AT, with a preferential inhibition in the epididymal fat [58]. Compatible with animal experiments, n3 PUFA inhibits adipocyte differentiation, induces apoptosis in postconfluent preadipocytes, and promotes lipolysis [92]. Additionally, oxidation may be also involved in the profound effects of n-3 PUFA on prevention of enlarged adipocytes. The effect of n-3 PUFA in abdominal fat is associated with increased expression of genes engaged in mitochondrial biogenesis and oxidative metabolism, contributing to the shrinkage of adipocytes [93]. It is worthwhile to mention that dietary n-3 PUFA counteracts accretion of body fat without inducing mitochondrial uncoupling protein 1 (UCP1) in AT, suggesting that the antiobesity effect is independent of adaptive thermogenesis [94]. However, conflicting results give rise to the question whether the reductive effect on body fat accumulation exerted by n-3 PUFA is attributed to both limited hypertrophy and hyperplasia of adipocytes. Treatment with n-3 PUFA results in a significant decrease in the size of mature adipocytes and accumulation of smaller adipocytes [95], possibly along with increased total number of adipocytes. It cannot be excluded that the formation of small adipocytes results not only from shrinkage of existing mature adipocytes, but also from the proliferation of preadipocyte due to the activation of PPAR $\gamma$ [96]. Taken together, it is reasonable to speculate that n-3 PUFA ameliorates adipocyte stress and normalizes adipocyte functions, especially secretory function.

It was initially assumed that inclusion of n-3 PUFA is associated with remarkable changes in the plasma levels of two key adipokines, adiponectin and leptin. Further studies demonstrate that the induction of adiponectin by n-3 PUFA is adiposity-independent, since reduction of fat content due to caloric restriction hardly regulates adiponectin levels $[90,97,98]$. Based on emerging data highlighting the negative regulation of n-3 PUFA on leptin [99], conflicting results demonstrate that, in contrast to adiponectin, plasma leptin levels decrease with caloric restriction, an effect depending on body fat mass [100]. We cannot exclude the possibility that alteration in leptin is secondary to inhibition of enlarged AT caused by n-3 PUFA, rather than a direct consequence of n-3 PUFA manipulation. Other adipokines visfatin and apelin are also regulated corresponding to n-3 PUFA treatment without alteration in circulating levels, suggesting that both of them are incompetent to mediate systemic influence [101]. With regard to proinflammatory mediators derived from AT, dietary interventions with n-3 PUFA have been found to reduce TNF- $\alpha$, IL- 6 levels in AT $[102,103]$. Given depot-specificity, n-3 PUFA reduces the expression of inflammatory genes of both gonadal and subcutaneous fat depots, suggesting the prevention against AT inflammatory may be apply to different fat depots [90]. The mechanism concerning adipocyte biological functions unveils that n-3 PUFA efficiently incorporates into AT, making their way into the membrane phospholipids and TAG lipid droplets, which is regarded as a mechanism for its preferential effects in AT [104-107]. Overall, these observations indicate that n-3 PUFA brings about a shift from a proinflammatory microenvironment to one of reduced inflammations (Figure 2).

5.3. Systemic Benefits. As mentioned, AT is responsible for the major form of crosstalk between insulin-responsive tissues. Thus, any treatment aimed at normalizing AT storage and secretory functions will alleviate the inflammatory state and lead to a global improvement in insulin sensitivity. Admittedly, the anti-inflammatory benefits of dietary n-3 PUFA involve modification in different tissues (liver, skeletal muscle, and AT) [108], which is not the interest of present review. Instead, this part is focused on systemic benefits of n-3 PUFA mediated by AT.

A large body of evidences demonstrates that n-3 PUFA reduces lipolysis in AT, resulting in reduced NEFA release into circulation $[52,108]$. The modulation of lipoprotein lipase, hormone-sensitive lipase and fatty acid synthase is proposed as a possible mechanism in which n-3 PUFA inhibits lipolysis in AT [109].

In parallel, beneficial effect of n-3 PUFA on systemic glucose and lipid homeostasis heavily relies on circulating levels of adiponectin that is recognized as a critical mediator in improving insulin sensitivity. Given its insulin-sensitizing effect, it makes sense that improved insulin action observed with n-3 PUFA treatment in adiposity, liver, and skeletal muscle is mediated by adiponectin. Of note, this adipocytederived hormone directly increases glucose utilization and fatty acid oxidation in liver and skeletal muscle via stimulating the activation of $5^{\prime}$-AMP-activated protein kinase (AMPK) [110] and PPAR $\gamma$ [111], which is considered as the answer to this insulin-sensitizing effect of adiponectin. Actually, recent molecular studies illuminate the signal transduction of adiponectin in muscle cells [112], warranting that stimulation of adiponectin secretion induces mitochondrial biogenesis.

Recent results have increased interest in the role of hypothalamus inflammation playing in the pathogenesis of obesity. As an early and determining factor in the installation and progression of obesity, hypothalamic inflammation is a cardinal mechanism leading to the anomalous control of energy intake and expenditure $[113,114]$. The substitution of saturated fat by n-3 PUFA in the diet reduces diet-induced hypothalamic inflammation and corrects the response to nutrient sensing signals [63].

N-3 PUFA minimizes the insulin resistance in high fat-fed mice in an adiponectin-dependent manner [100]. 


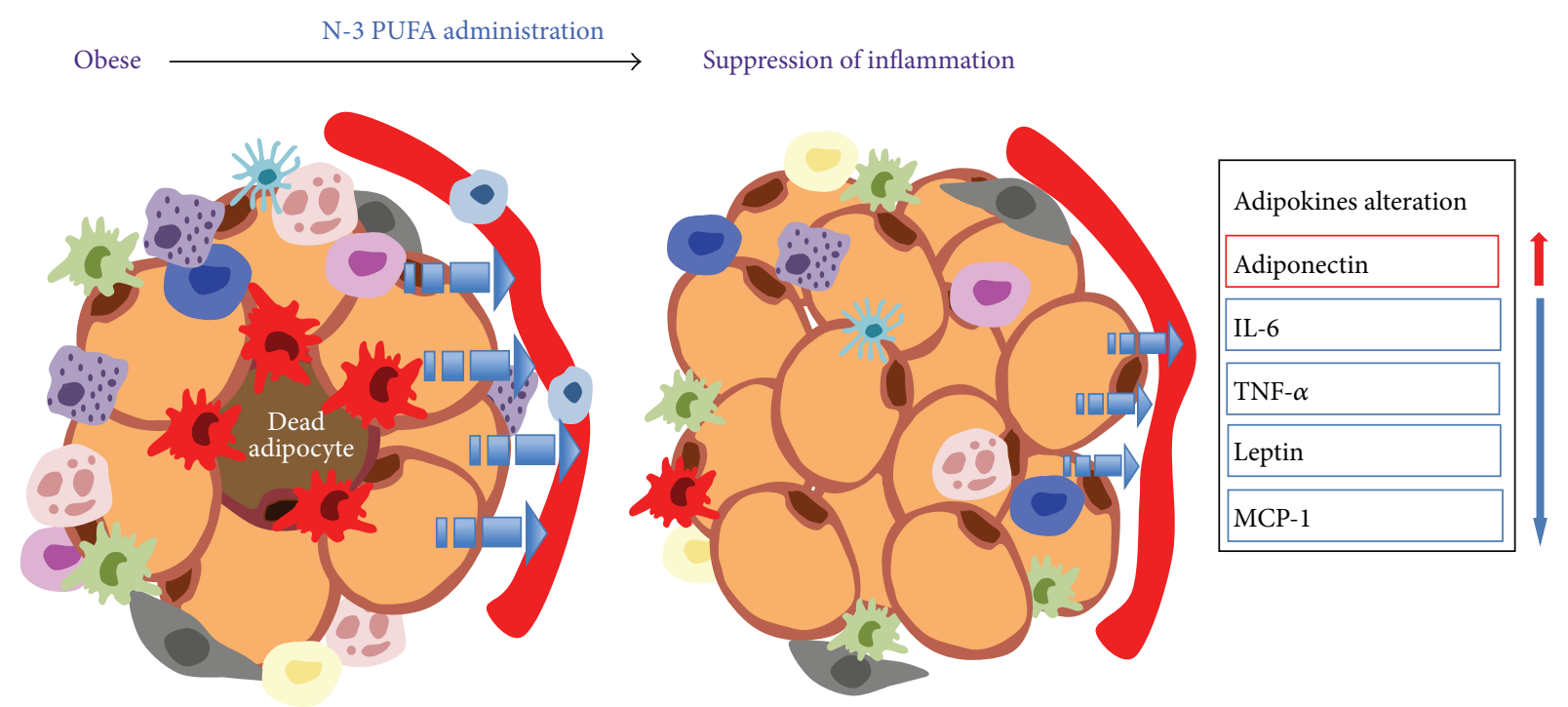

FIgURE 2: Mitigation of AT local inflammation by n-3 PUFA as a result from normalization of AT storage and secretory function. In the presence of n-3 PUFA, it is clear that the population of small adipocytes increases, possibly with unchanged total fat mass due to reduced large adipocyte. Alteration in cellularity also includes reduced ATM content, along with transformation from M1 to M2 polarization state. The last confirmed observation is dramatically modified adipokine secretion.

Additionally, insulin and nonesterified fatty acid are also affected predominantly by n-3 PUFA administration [100]. Taken together, the beneficial effects of n-3 PUFA on metabolic derangements are mediated in part by alleviation of AT inflammation, especially resulting from decreased secretion of proinflammatory adipokines, increased secretion of adiponectin, and induced synthesis of proresolving lipid mediators.

\section{Intracellular Regulatory Mechanism Affected by n-3 PUFA}

The previous section summarizes the broad range of antiinflammatory actions exerted by n-3 PUFA. Various mechanisms are directly or indirectly involved in explaining the influence of n-3 PUFA on metabolic events, including, but not limited to, the changes in membrane composition and intracellular metabolite levels concerning signaling pathways (Figure 3). Here, four approaches which are identified as the molecular targets of the anti-inflammatory effect of n3 PUFA are described in detail, since the transcription of inflammatory genes determines the production of inflammatory cytokines by certain cells, which plays a direct as well as central role in inflammatory cascade. Activity of transcription factors mastering the inflammatory signaling will potentially modulate inflammation. Moreover, the integration of important cell-signaling pathways engaged in $n-3$ PUFA-mediated anti-inflammatory functions has only begun to be investigated and has not yet been clearly defined. A former review summarizes that the major role for PPARs is in the trans-suppression of inflammatory gene activation by negatively interfering with the nuclear factor $\kappa \mathrm{B}$ (NF$\kappa \mathrm{B})$ [115]. In $\mathrm{C} 2 \mathrm{C} 12$ myotubes, we have discovered that the suppressive effect of EPA on NF- $\kappa$ B activation is mediated via
PPAR $\gamma$ activation [116]. Similarly, the expression of PPAR $\gamma$ in LPS-stimulated macrophages augments the inhibitory effect of inhibitor on NF- $\kappa$ B activity [117]. As a complement to above observation, Zúñiga and colleagues [118] figure out an antagonistic effect of PPAR $\alpha$ on NF- $\kappa$ B-controlled transcription of pro-inflammatory mediators.

6.1. Membrane Phospholipid Fatty Acid Profile. PUFA is a key structural and functional component of the phospholipids in cell membranes and the most common PUFA in the membrane phospholipids of macrophages, neutrophils, and lymphocytes is the n-6 PUFA AA [53]. In contrast to high proportion of AA, much less EPA and DHA are found in the cell membrane phospholipids. However, n-3 PUFA supplement in the diet of animals or healthy human demonstrates a significant incorporation of EPA and DHA into total AT lipids, liver TAG and phospholipid fractions, and brain phospholipids [119]. Corresponding to n-3 PUFA supplementation, mice exhibit the accumulation of $n-3$ PUFA in membrane phospholipids of immune cells coupled with reduced AA content [77]. The increased proportion of $n-$ 3 PUFA in the membrane phospholipids likely contributes to its anti-inflammatory effect of inhibiting production of proinflammatory mediators secreted by mononuclear cells [85]. As mentioned before, similar incorporation is observed in adipocytes. Researches attempting to illuminate the influence of dietary n-3 PUFA on the lipid composition and metabolism of adipocytes disclose that rats fed the n-3 PUFA have significantly lower concentrations of serum triglycerides, cholesterol, and insulin, concomitant with higher unsaturated to saturated fatty acid ratio observed in adipocyte membrane phospholipids [105]. Conceivably, the improvement of insulin sensitivity is also positively correlated with 


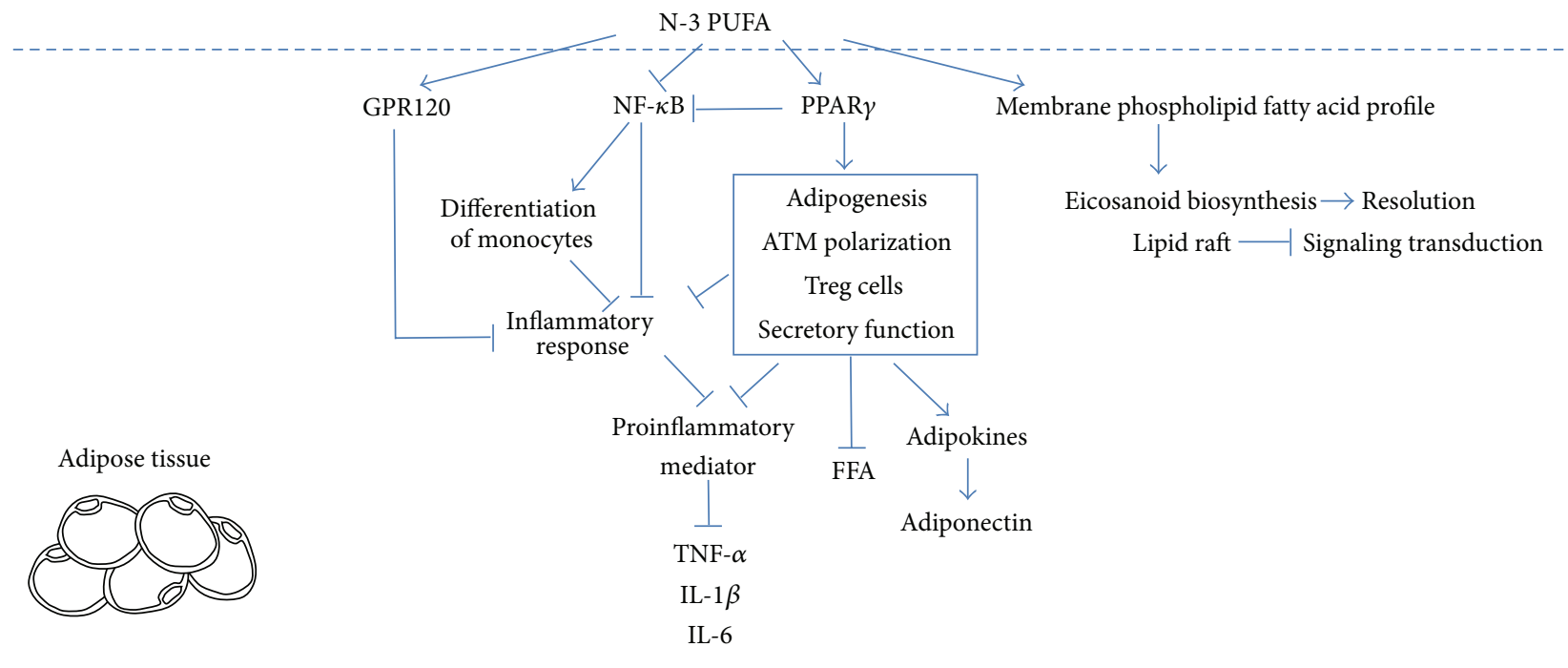

Normalization of AT function and relief of local inflammation

Suppression of ectopic deposition

Restoration of systemic insulin sensitivity

Preservation of glucose homeostasis

Induced mitochondrial biogenesis

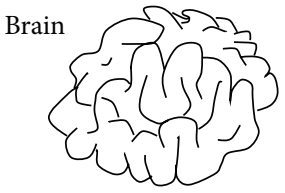

Control of energy intake and expenditure $\uparrow$

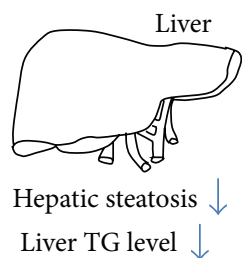

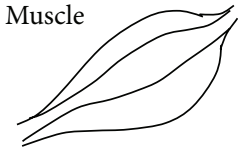

Glucose disposal $\uparrow$

Figure 3: Putative mechanism by which adipose tissue mediates the systemic benefits derived from n-3 PUFA consumption. N-3 PUFA reduces adipose tissue inflammation via changing membrane phospholipid composition and activity of signaling pathways. The manipulation of membrane phospholipids composition and lipid raft microdomain with n-3 PUFA modify downstream processes mediated by membrane, such as signaling transduction, gene expression, and eicosanoid biosynthesis. Increased biosynthesis of resolvin and protectin contributes to resolution process. PPAR $\gamma$ activation mediated by n-3 PUFA leads to increased number of small adipocytes, M2 macrophages, and Treg cells, while normalizing secretory function featured by induced adiponectin synthesis, inhibited lipolysis, and reduced pro-inflammatory mediator secretion. As anticipated, NF- $\kappa$ B inhibition, which is partly dependent on PPAR $\gamma$ activation, downregulates the expression of proinflammatory gene directly and indirectly via determining the differentiation of monocytes. GPR120 is the functional receptor making response to n-3 PUFA and mediates the anti-inflammatory benefits by repressing several inflammatory signalings. The improved storage and secretory functions of adipose tissue lead to relief of AT-specific inflammation, followed by global improvement of metabolic profile. Adiposespecific blunting of inflammation primarily favors the functional improvement of several organ systems involving liver, skeletal muscle, and brain.

higher incorporation of n-3 PUFA in adipocyte membrane phospholipids [104].

It is thought that n-3 PUFA displaces AA from plasma membranes, decreasing its availability as a precursor of inflammation associated mediators. Inhibitory effect of n-3 PUFA on the release of substrate AA also is attributed to the suppressed phospholipase activity [76]. Irrespective of substrate accessibility, alteration of metabolites results from decreased AA metabolism due to the inhibition of cyclooxygenase (COX) activity [120]. This seems the possible explanation for the mechanism in which n-3 PUFA affects lipidmediator profiles. The n-3 PUFA substitution of AA into adipocyte membrane phospholipids results in decreased level of prostaglandin $\mathrm{E}_{2}\left(\mathrm{PGE}_{2}\right)$ and subsequent downregulated fatty acid synthesis enzyme activity [69], which curbs adipocyte hypertrophic. On the other hand, decreased formation of prostaglandin D2 (PGD2) and its derivatives, known as PPAR $\gamma$ ligands, presumably explains the effects of $n-3$ PUFA on proliferation and maturation of adipocytes [44]. Interestingly, insulin action is positively correlated with the fatty acid unsaturation index in membrane [104], whereas related mechanism remains obscure.

A second aspect of the alternation in cell membrane phospholipid fatty acid involves lipid raft in which key signal transduction proteins are localized, such as the tyrosine kinase lck and the signaling molecule linker of activated $\mathrm{T}$ 
cells [121]. Exposed to n-3 PUFA treatment, Jurkat T cell ends in marked enrichment of n-3 PUFA in lipids from isolated raft, with selective displacement of signaling proteins from raft in PUFA-treated $\mathrm{T}$ cells due to altered raft lipid composition [122]. Later data collectively demonstrate that modified raft lipid environment affects the membrane subdomain distribution of proteins involved in the interleukin2 receptor (IL-2R) and toll-like receptor (TLR-4) signaling pathway $[123,124]$. For now, disrupting rafts with n-3 PUFA and subsequent impact on immune cell function are centered on T cells, macrophages, and B cells, considered as the answer to immunosuppression property of n-3 PUFA.

The manipulation of membrane phospholipids composition and lipid raft microdomain with n-3 PUFA modify downstream processes mediated by membrane, such as signaling transduction, gene expression, and eicosanoid biosynthesis.

6.2. Peroxisome Proliferator-Activator Receptors (PPARs). As lipid-activated transcription factors, PPARs contribute to attenuating inflammatory response. Numerous agonists of the related receptor PPAR have anti-inflammatory activity $[125,126]$. Thiazolidinedione- (TZD-) induced activation of PPAR $\gamma$ is reported to relieve hyperglycemia, hyperinsulinemia in vivo, reducing secretion of FFA, TNF- $\alpha$, and leptin concomitantly [96]. PPAR $\gamma$, originally described in differentiating adipocytes, severs as a master regulator of adipogenesis and the target for the insulin-sensitizing drugs [127, 128]. Admittedly, forced expression of PPAR $\gamma$ in the fibroblasts makes them differentiate into adipocytes [129] and activation of PPAR $\gamma$ indeed contributes to increasing population of small adipocytes, but the total mass or the total triglyceride content of WAT remains unchanged with the number of large adipocytes decreasing [96]. Compared with large mature adipocytes, small immature ones seem less competent in secreting proinflammatory cytokines [130]. This shift toward smaller adipocytes seems to be partially responsible for the favorable metabolic effects of PPAR $\gamma$ activators. With regard to the secretion of adipokines, PPAR $\gamma$ agonists have been reported to increase circulating levels of adiponectin [131]. Moreover, PPAR $\gamma$ null mice and in vitro experiments all demonstrate that the increased synthesis and secretion of adipokines by n-3 PUFA are dependent on $\operatorname{PPAR} \gamma[132,133]$.

The expression of PPAR $\gamma$ is also observed in cells of immune system and central nervous system. PPAR $\gamma$ activation stimulated by short-term glitazones treatment increases infiltration of M2 in AT [134]. Macrophage-specific disruption of PPAR $\gamma$ impairs development of alternatively activated M2 phenotype and predisposes individuals to dietinduced obesity [135]. Providing that PPAR $\gamma$ is indispensable in the development of M2 phenotype, PPAR $\gamma$ inactivation indirectly increases production of proinflammatory cytokine [136]. Similarly, PPAR $\gamma$ activation suppresses monocyte elaboration of proinflammatory cytokines, including IL- $1 \beta$, TNF$\alpha$, and IL-6 [137]. Unexpectedly, inactivation of PPAR $\gamma$ in macrophages has unimaginable broad effects on significant glucose intolerance and impaired whole-body insulin resistance in lean mice fed a normal diet [136]. VAT-resident
Foxp $^{+}$Treg cells also specifically express PPAR $\gamma$ which interacts with Foxp3 [138]. Foxp3-dependent PPAR $\gamma$ conditional knockout mice demonstrate that Treg cell-specific deletion of PPAR $\gamma$ leads to reduced number of Treg cells specifically in VAT, resulting in an increase in VAT infiltration of macrophages and monocytes. Additionally, stimulation with TZD drugs specifically increases VAT-resident Treg cells in the obese mice fed high-fat diet, with improving insulin sensitivity synchronically. These results collectively indicate that the therapeutic effect of TZD drugs partly is attributed to accumulation of Foxp $3^{+}$Treg cells in VAT. Naturally occurring Foxp $3^{+}$Treg cells produced by thymus possibly sense activator, as a result, PPAR $\gamma$ expression is upregulated with migration of Foxp $3^{+}$Treg cells to the VAT. Alternatively, in parallel with accumulation of VAT-resident Foxp $3^{+}$Treg cells, augmentation of such suppressive activities of PPAR $\gamma$ expressing Treg cells achieved by ligand activation may enable better control of inflammation in obesity.

In conclusion, PPAR $\gamma$ may act on differentiating adipocytes, macrophages, and Treg cells to alleviate AT inflammation and restore insulin sensitivity. The other mechanism involved in the effect of PPAR $\gamma$ on anti-inflammation remains further investigation. High concentration of n-3 PUFA has been reported to be active $\operatorname{PPAR} \gamma$, whereas their metabolites are stronger agonists [139]. Anti-inflammatory effects of n-3 PUFA are known to act at least in part through activation of PPAR $\gamma$. Although this speculation seems arguable, since n6 PUFA, the stronger activator of $\operatorname{PPAR} \gamma$, exhibits opposite effects. However, we are supposed to keep in mind that $\mathrm{n}$ 6 PUFA likely assumes their proinflammatory responsibility via other mechanism which is powerful enough to counteract the anti-inflammatory effect mediated by activation of $\operatorname{PPAR} \gamma$.

Another candidate mechanism responsible for the antiinflammatory action of n-3 PUFA is the removal of detrimental eicosanoids via $\beta$-oxidation, which is likely stimulated by PPAR activation [140].

6.3. Nuclear Factor $\kappa B(N F-\kappa B)$. Consistent with its central role in inflammatory signaling pathways, NF- $\kappa \mathrm{B}$ is widely investigated in the linkage between inflammatory and metabolic responses. Once activated by extracellular stimuli, $\mathrm{NF}-\kappa \mathrm{B}$ promotes inflammation through initiating expression of genes encoding for inflammatory-related proteins in a very wide range of cell types, including macrophages, hepatocytes, and adipocytes. Additionally, NF- $\kappa \mathrm{B}$ directs the differentiation of distinct immune cell types by regulating expression of inflammatory mediators. NF- $\kappa \mathrm{B}$-dependent differentiation of monocytes into either M1 or M2 macrophages in response to cytokines produced by immune cells also accounts for the involvement of $\mathrm{NF}-\kappa \mathrm{B}$ in inflammation associated metabolic disorders, taking distinctive functions of M1 and M2 macrophages into consideration. Furthermore, activated NF- $\kappa \mathrm{B}$ promotes macrophage relocalization and activation, and more proinflammatory cytokines secretion augments macrophage activation and recruitment to the inflamed site [141]. Unexpectedly, different from a local and modest inflammatory response caused by IKK- $\beta$ induced 
NF- $\kappa$ B activation in hepatocytes [142], inactivation due to IKK- $\beta$ deficiency in myeloid cells favors global insulin sensitivity [143]. Additionally, inactivation of NF- $\kappa$ B by IKK- $\beta$ deletion significantly diminishes the expression of inflammatory mediators [144]. Not only in peripheral metabolic tissues, recent study even discloses that in hypothalamus, NF$\kappa \mathrm{B}$ which functions as the pro-inflammatory master switch is blamed for dysregulation of energy balance after sensing metabolic signals produced by overnutrition [113]. Brightly discriminated from the inflammatory reactions featured by chaotic release and powerful action of many inflammatory cytokines in nonneuronal cells, forced activation of hypothalamic IKK- $\beta / \mathrm{NF}-\kappa \mathrm{B}$ interrupts central insulin/leptin signaling and actions in a neuron-specific and noncytokine way, resulting in increased intake of high-fat food and weight gain. By contrast, suppression of IKK- $\beta$ either broadly or locally significantly protects against obesity and glucose intolerance [113], suggesting that inflammatory response in the peripheral metabolic loci trigged by overnutrition no longer causes functional defect in tissue-specific manner. Instead, metabolic inflammation and related inflammatory mediator are connected to the dysfunctions in the central nervous system.

In the quiescent state, NF- $\kappa \mathrm{B}$ remains inactive in the cytoplasm binding to the inhibitory protein $\mathrm{I} \kappa \mathrm{B}$. Phosphorylation of this inhibitory subunit releases NF- $\kappa \mathrm{B}$, followed by NF- $\kappa \mathrm{B}$ translocation into nucleus where it controls the transcription of its target genes. Consistent with other researches based on THP-1 cells [87], we have found that n-3 PUFA inhibits $\mathrm{NF}-\kappa \mathrm{B}$ activity in myotubes in vitro by preventing the degradation of $\mathrm{I} \kappa \mathrm{B} \alpha$ [145]. The explanation for the regulation of cytokines production caused by n-3 PUFA is the changes in inflammatory gene expression, which is partly ascribed to $\mathrm{NF}-\kappa \mathrm{B}$ suppression with decreased $\mathrm{I} \kappa \mathrm{B}$ phosphorylation $[86$, 87]. Notably, NF- $\kappa$ B is enhanced or unaffected with saturated fatty acids and n-6 PUFA treatments $[86,146]$, validating that the inactivation of NF- $\kappa$ B is exclusive to n-3 PUFA instead of a general lipid effect. Based on accessible reports, inhibitory effects of n-3 PUFA on NF- $\kappa$ B activation lead to related gene expression, including IL-1, IL- $1 \beta$, and TNF- $\alpha$.

6.4. G Protein-Coupled Receptor 120. It has been reported previously that G protein-coupled receptor 120 (GPR120) functions as a signaling molecule for a wide array of cellular functions in response to unsaturated long-chain FAs [147]. Tissue expression pattern further indicates that GPR120 is the only lipid sensing GPR highly expressed in specialized proinflammatory tissue and cells [59], suggesting its critical role in development of obesity. Subsequent researches using human genetics approaches identify loss-of-function GPR120 gene variants that caused increased incidence of obesity and related sequelae, especially in the context of high-fat diet [148]. Interestingly, dysfunctional receptor underscores the inefficiency to transduce the signal of long-chain fatty acid [148], opening novel avenues of researches for antiobesity effects associated with n-3 PUFA. Actually, it has been already confirmed that GPR120 is the functional receptor making response to n-3 PUFA and mediates the anti-inflammatory benefits by repressing TRL2/3/4 and TNF- $\alpha$ inflammatory signaling in a $\beta$-arrestin2 dependent way, coupled with insulin sensitizing actions [59]. In more detail, following n-3 PUFA-stimulated internalization of the GPR120/ $\beta$-arrestin2 complex, $\beta$-arrestin 2 associates with TAK1 binding protein 1 (TAB1), blocking the association of TAB1 with activated kinase 1 (TAK1), which dampens downstream signaling to the IKK $\beta / \mathrm{NF}-\kappa \mathrm{B}$ and JNK/AP1 system [59]. A similar receptor dependency for the anti-inflammatory effects of n-3 PUFA is observed in hypothalamus and Kupffer cells [63, 91].

\section{Conclusion}

Prolonged nutrient excess elicits infiltration of macrophages and other immune cells in AT, resulting in uncontrolled secretion of proinflammatory cytokines and a state of chronic low-grade inflammation. In turn, these released cytokines affect other organs, such as skeletal muscle, liver, and brain, ultimately ending up with metabolic abnormalities systemically. Undoubtedly, AT is the epicenter of the obesity, since inflamed AT is the primary source blamed for proinflammatory cytokines. The overall impacts of n-3 PUFA on AT biology and metabolism fall into three categories: storage, secretory function, and inflammation. Decreased storage and normalized secretion finally achieve adipose-specific blunting of inflammation. Aligning with the emerging view, AT lies at the crossroad of nutrient sensing, metabolism, inflammation, and endocrine. As anticipated, results from clinical and molecular studies have converged to highlight the broad spectrum of protective effects of n-3 PUFA in obesity and comorbidity. There is considerable crosstalk between AT and a wide array of organs, underscoring the difficulty in dissecting tissue-specific effects of n-3 PUFA and additional benefits mediated by AT. Recapitulating the phenotypical and metabolic date, we easily come to the conclusion that specific treatment results in a certain phenotype. However, elevated circulating adiponectin derived from AT due to dietary n-3 PUFA is an easily ignored contributor to restoration of insulin signaling in liver and muscle. Identification of the "missing link" between treatment and direct executor is an important next step towards our understanding of the actions of n-3 PUFA.

More recently, nutrients and environmental factors have been shown to induce epigenetic modifications [149], which is definitely a most rapidly expanding field in biology. Mapping of epigenetic marks, such as DNA methylation, histone modifications, and nucleosome positioning, is critical for understanding the regulatory mechanism for gene expression, chromatin remodeling factors, and noncoding RNA expression influenced by diet constitutes. Since the pathophysiology of obesity is concomitant with extensive gene expression changes, special emphasis is put on identification epigenetic changes induced by obesity and mechanism through which epigenetics contribute to obesity [150]. It would appear that future studies might be needed to establish and validate the relationship between dietary n-3 PUFA and antiobesity effect and how epigenetic mechanism may link them. Although the effect of dietary n-3 PUFA on the 
increased expression of leptin seems unrelated to promoter CpG methylation, given that feeding mice with n-3 PUFA diet is unable to affect $\mathrm{CpG}$ methylation in the leptin gene promoters [151]. The reasonable explanation may be the irrelevance between n-3 PUFA and increased leptin, which has been suggested before. Otherwise, we cannot rule out the possibility that histone modification, rather than DNA methylation, is the determinant elucidating the regulatory influence of n-3 PUFA on leptin expression in obesity.

The fact that not all AT expansion is necessarily associated with pathological changes makes us rethink our understanding towards obesity. Despite having excessive fat accumulation, a unique subset of obese individuals seem metabolically healthy, bypassing all of the aforementioned pathological phenotype associated with obesity [152]. It is supposed to reconsider and revalue obesity professionally in terms of metabolic disturbances and metabolic parameters, rather than arbitrary judgment based on fat mass. Accordingly, n3 PUFA is never a panacea for dramatic loss of AT mass compared with energy restriction, but it is proficient in protecting from obesity-induced metabolic abnormalities, regardless of weight loss. In this regard, n-3 PUFA is a qualified nutritional regimen fighting against metabolic disorders. The anti-inflammatory and immune-regulatory effects of n-3 PUFA would be the hot issue worthy of further investigation rather than having antiobesity effects as the endpoint.

\section{Conflict of Interests}

The authors declare that there is no conflict of interests regarding the publication of this paper.

\section{Acknowledgments}

The authors would like to thank members of their laboratory for helpful and constructive advice. At the same time, they also thank National Natural Science Foundation of China (Grant no. 31101722) and Specialized Research Fund for the Doctoral Program of Higher Education (Grant no. 20110146120004) providing financial support for their previous experiments.

\section{References}

[1] H. Xu, G. T. Barnes, Q. Yang et al., "Chronic inflammation in fat plays a crucial role in the development of obesity-related insulin resistance," The Journal of Clinical Investigation, vol. 112, no. 12, pp. 1821-1830, 2003.

[2] K. E. Wellen and G. S. Hotamisligil, "Obesity-induced inflammatory changes in adipose tissue," The Journal of Clinical Investigation, vol. 112, no. 12, pp. 1785-1788, 2003.

[3] M. Mraz and M. Haluzik, "The role of adipose tissue immune cells in obesity and low-grade inflammation," Journal of Endocrinology, vol. 222, no. 3, pp. R113-R127, 2014.

[4] E. D. Rosen and B. M. Spiegelman, "What we talk about when we talk about fat," Cell, vol. 156, no. 1-2, pp. 20-44, 2014.

[5] C. N. Lumeng and A. R. Saltiel, "Inflammatory links between obesity and metabolic disease," The Journal of Clinical Investigation, vol. 121, no. 6, pp. 2111-2117, 2011.
[6] P. C. Calder, " $n-3$ polyunsaturated fatty acids, inflammation, and inflammatory diseases," The American Journal of Clinical Nutrition, vol. 83, no. 6, supplement, pp. 1505S-1519S, 2006.

[7] A. P. Simopoulos, "Omega-3 fatty acids in inflammation and autoimmune diseases," The Journal of the American College of Nutrition, vol. 21, no. 6, pp. 495-505, 2002.

[8] Z. P. Zhan, F. R. Huang, J. Luo, J. J. Dai, X. H. Yan, and J. Peng, "Duration of feeding linseed diet influences expression of inflammation-related genes and growth performance of growing-finishing barrows," Journal of Animal Science, vol. 87, no. 2, pp. 603-611, 2009.

[9] K. Kang, S. M. Reilly, V. Karabacak et al., "Adipocyte-derived Th2 cytokines and myeloid PPAR $\delta$ regulate macrophage polarization and insulin sensitivity," Cell Metabolism, vol. 7, no. 6, pp. 485-495, 2008.

[10] G. S. Hotamisligil, P. Arner, J. F. Caro, R. L. Atkinson, and B. M. Spiegelman, "Increased adipose tissue expression of tumor necrosis factor- $\alpha$ in human obesity and insulin resistance," The Journal of Clinical Investigation, vol. 95, no. 5, pp. 2409-2415, 1995.

[11] K. E. Wellen and G. S. Hotamisligil, "Inflammation, stress, and diabetes," The Journal of Clinical Investigation, vol. 115, no. 5, pp. 1111-1119, 2005.

[12] J.-P. Bastard, M. Maachi, C. Lagathu et al., "Recent advances in the relationship between obesity, inflammation, and insulin resistance," European Cytokine Network, vol. 17, no. 1, pp. 4-12, 2006.

[13] G. S. Hotamisligil, "Inflammation and metabolic disorders," Nature, vol. 444, no. 7121, pp. 860-867, 2006.

[14] C. A. Curat, A. Miranville, C. Sengenès et al., "From blood monocytes to adipose tissue-resident macrophages. Induction of diapedesis by human mature adipocytes," Diabetes, vol. 53, no. 5, pp. 1285-1292, 2004.

[15] E. D. Rosen and B. M. Spiegelman, "Adipocytes as regulators of energy balance and glucose homeostasis," Nature, vol. 444, no. 7121, pp. 847-853, 2006.

[16] G. S. Hotamisligil, N. S. Shargill, and B. M. Spiegelman, "Adipose expression of tumor necrosis factor- $\alpha$ : direct role in obesity-linked insulin resistance," Science, vol. 259, no. 5091, pp. 87-91, 1993.

[17] J. G. Neels and J. M. Olefsky, "Inflamed fat: what starts the fire?" The Journal of Clinical Investigation, vol. 116, no. 1, pp. 33-35, 2006.

[18] N. Kamei, K. Tobe, R. Suzuki et al., "Overexpression of monocyte chemoattractant protein-1 in adipose tissues causes macrophage recruitment and insulin resistance," The Journal of Biological Chemistry, vol. 281, no. 36, pp. 26602-26614, 2006.

[19] H. Kanda, S. Tateya, Y. Tamori et al., "MCP-1 contributes to macrophage infiltration into adipose tissue, insulin resistance, and hepatic steatosis in obesity," The Journal of Clinical Investigation, vol. 116, no. 6, pp. 1494-1505, 2006.

[20] A. Soukas, P. Cohen, N. D. Socci, and J. M. Friedman, "Leptinspecific patterns of gene expression in white adipose tissue," Genes \& Development, vol. 14, no. 8, pp. 963-980, 2000.

[21] S. P. Weisberg, D. McCann, M. Desai, M. Rosenbaum, R. L. Leibel, and A. W. Ferrante Jr., "Obesity is associated with macrophage accumulation in adipose tissue," The Journal of Clinical Investigation, vol. 112, no. 12, pp. 1796-1808, 2003.

[22] R. Cancello, C. Henegar, N. Viguerie et al., "Reduction of macrophage infiltration and chemoattractant gene expression changes in white adipose tissue of morbidly obese subjects after 
surgery-induced weight loss," Diabetes, vol. 54, no. 8, pp. 22772286, 2005.

[23] A. W. Ferrante Jr., "Obesity-induced inflammation: a metabolic dialogue in the language of inflammation," Journal of Internal Medicine, vol. 262, no. 4, pp. 408-414, 2007.

[24] C. N. Lumeng, J. L. Bodzin, and A. R. Saltiel, "Obesity induces a phenotypic switch in adipose tissue macrophage polarization," The Journal of Clinical Investigation, vol. 117, no. 1, pp. 175-184, 2007.

[25] S. Cinti, G. Mitchell, G. Barbatelli et al., "Adipocyte death defines macrophage localization and function in adipose tissue of obese mice and humans," Journal of Lipid Research, vol. 46, no. 11, pp. 2347-2355, 2005.

[26] K. Sun, C. M. Kusminski, and P. E. Scherer, "Adipose tissue remodeling and obesity," The Journal of Clinical Investigation, vol. 121, no. 6, pp. 2094-2101, 2011.

[27] V. Catalán, J. Gómez-Ambrosi, A. Rodríguez, and G. Frühbeck, "Role of extracellular matrix remodelling in adipose tissue pathophysiology: relevance in the development of obesity," Histology and Histopathology, vol. 27, no. 12, pp. 1515-1528, 2012.

[28] P. Trayhurn, "Hypoxia and adipose tissue function and dysfunction in obesity," Physiological Reviews, vol. 93, no. 1, pp. 1-21, 2013.

[29] P. Trayhurn, B. Wang, and I. S. Wood, "Hypoxia and the endocrine and signalling role of white adipose tissue," Archives of Physiology and Biochemistry, vol. 114, no. 4, pp. 267-276, 2008.

[30] T. Khan, E. S. Muise, P. Iyengar et al., "Metabolic dysregulation and adipose tissue fibrosis: role of collagen VI," Molecular and Cellular Biology, vol. 29, no. 6, pp. 1575-1591, 2009.

[31] J. M. Way, W. W. Harrington, K. K. Brown et al., "Comprehensive messenger ribonucleic acid profiling reveals that peroxisome proliferator-activated receptor $\gamma$ activation has coordinate effects on gene expression in multiple insulin-sensitive tissues," Endocrinology, vol. 142, no. 3, pp. 1269-1277, 2001.

[32] S. Z. Josefowicz, L.-F. Lu, and A. Y. Rudensky, "Regulatory T cells: mechanisms of differentiation and function," Annual Review of Immunology, vol. 30, pp. 531-564, 2012.

[33] M. Feuerer, L. Herrero, D. Cipolletta et al., "Lean, but not obese, fat is enriched for a unique population of regulatory $\mathrm{T}$ cells that affect metabolic parameters," Nature Medicine, vol. 15, no. 8, pp. 930-939, 2009.

[34] P. A. Kern, M. Saghizadeh, J. M. Ong, R. J. Bosch, R. Deem, and R. B. Simsolo, "The expression of tumor necrosis factor in human adipose tissue: regulation by obesity, weight loss, and relationship to lipoprotein lipase," The Journal of Clinical Investigation, vol. 95, no. 5, pp. 2111-2119, 1995.

[35] E. J. Park, J. H. Lee, G.-Y. Yu et al., "Dietary and genetic obesity promote liver inflammation and tumorigenesis by enhancing IL-6 and TNF expression," Cell, vol. 140, no. 2, pp. 197-208, 2010.

[36] H. Xu, K. T. Uysal, J. D. Becherer, P. Arner, and G. S. Hotamisligil, "Altered tumor necrosis factor- $\alpha$ (TNF- $\alpha$ ) processing in adipocytes and increased expression of transmembrane TNF$\alpha$ in obesity," Diabetes, vol. 51, no. 6, pp. 1876-1883, 2002.

[37] K. T. Uysal, S. M. Wiesbrock, M. W. Marino, and G. S. Hotamisligil, "Protection from obesity-induced insulin resistance in mice lacking TNF- $\alpha$ function," Nature, vol. 389, no. 6651, pp. 610-614, 1997.

[38] G. Winkler, P. Lakatos, F. Salamon et al., "Elevated serum TNF$\alpha$ level as a link between endothelial dysfunction and insulin resistance in normotensive obese patients," Diabetic Medicine, vol. 16, no. 3, pp. 207-211, 1999.
[39] P. A. Kern, S. Ranganathan, C. Li, L. Wood, and G. Ranganathan, "Adipose tissue tumor necrosis factor and interleukin-6 expression in human obesity and insulin resistance," American Journal of Physiology: Endocrinology and Metabolism, vol. 280, no. 5, pp. E745-E751, 2001.

[40] F. Ofei, S. Hurel, J. Newkirk, M. Sopwith, and R. Taylor, "Effects of an engineered human anti-TNF- $\alpha$ antibody (CDP571) on insulin sensitivity and glycemic control in patients with NIDDM," Diabetes, vol. 45, no. 3, pp. 881-885, 1996.

[41] N. Paquot, M. J. Castillo, P. J. Lefèbvre, and A. J. Scheen, "No increased insulin sensitivity after a single intravenous administration of a recombinant human tumor necrosis factor receptor: Fc fusion protein in obese insulin-resistant patients," Journal of Clinical Endocrinology \& Metabolism, vol. 85, no. 3, pp. 1316-1319, 2000.

[42] H. Tilg and A. R. Moschen, "Adipocytokines: mediators linking adipose tissue, inflammation and immunity," Nature Reviews Immunology, vol. 6, no. 10, pp. 772-783, 2006.

[43] K. L. Donnelly, C. I. Smith, S. J. Schwarzenberg, J. Jessurun, M. D. Boldt, and E. J. Parks, "Sources of fatty acids stored in liver and secreted via lipoproteins in patients with nonalcoholic fatty liver disease," The Journal of Clinical Investigation, vol. 115, no. 5, pp. 1343-1351, 2005.

[44] P. Flachs, M. Rossmeisl, M. Bryhn, and J. Kopecky, "Cellular and molecular effects of n-3 polyunsaturated fatty acids on adipose tissue biology and metabolism," Clinical Science, vol. 116, no. 1, pp. 1-16, 2009.

[45] S. E. McQuaid, L. Hodson, M. J. Neville et al., "Downregulation of adipose tissue fatty acid trafficking in obesity: a driver for ectopic fat deposition?” Diabetes, vol. 60, no. 1, pp. 47-55, 2011.

[46] K. A. Britton and C. S. Fox, "Ectopic fat depots and cardiovascular disease," Circulation, vol. 124, no. 24, pp. e837-e841, 2011.

[47] J. F. Caro, J. W. Kolaczynski, M. R. Nyce et al., "Decreased cerebrospinal-fluid/serum leptin ratio in obesity: a possible mechanism for leptin resistance," The Lancet, vol. 348, no. 9021, pp. 159-161, 1996.

[48] R. Cancello, J. Tordjman, C. Poitou et al., "Increased infiltration of macrophages in omental adipose tissue is associated with marked hepatic lesions in morbid human obesity," Diabetes, vol. 55, no. 6, pp. 1554-1561, 2006.

[49] D. Patsouris, P.-P. Li, D. Thapar, J. Chapman, J. M. Olefsky, and J. G. Neels, "Ablation of CD1lc-positive cells normalizes insulin sensitivity in obese insulin resistant animals," Cell Metabolism, vol. 8, no. 4, pp. 301-309, 2008.

[50] S. Fujisaka, I. Usui, A. Bukhari et al., "Regulatory mechanisms for adipose tissue M1 and M2 macrophages in diet-induced obese mice," Diabetes, vol. 58, no. 11, pp. 2574-2582, 2009.

[51] A. S. Rossi, Y. B. Lombardo, and A. G. Chicco, "Lipogenic enzyme activities and glucose uptake in fat tissue of dyslipemic, insulin-resistant rats: effects of fish oil," Nutrition, vol. 26, no. 2, pp. 209-217, 2010.

[52] M. J. Puglisi, A. H. Hasty, and V. Saraswathi, "The role of adipose tissue in mediating the beneficial effects of dietary fish oil," The Journal of Nutritional Biochemistry, vol. 22, no. 2, pp. 101-108, 2011.

[53] P. C. Calder, "Omega-3 polyunsaturated fatty acids and inflammatory processes: nutrition or pharmacology?" British Journal of Clinical Pharmacology, vol. 75, no. 3, pp. 645-662, 2013.

[54] P. M. Kris-Etherton, W. S. Harris, and L. J. Appel, "Fish consumption, fish oil, omega-3 fatty acids, and cardiovascular disease," Circulation, vol. 106, no. 21, pp. 2747-2757, 2002. 
[55] J. Delarue, C. LeFoll, C. Corporeau, and D. Lucas, "n-3 long chain polyunsaturated fatty acids: a nutritional tool to prevent insulin resistance associated to type 2 diabetes and obesity?" Reproduction Nutrition Development, vol. 44, no. 3, pp. 289-299, 2004.

[56] F. Belzung, T. Raclot, and R. Groscolas, "Fish oil n-3 fatty acids selectively limit the hypertrophy of abdominal fat depots in growing rats fed high-fat diets," American Journal of Physiology-Regulatory Integrative and Comparative Physiology, vol. 264, no. 6, pp. R1111-R1118, 1993.

[57] T. Raclot, R. Groscolas, D. Langin, and P. Ferré, "Site-specific regulation of gene expression by $n-3$ polyunsaturated fatty acids in rat white adipose tissues," Journal of Lipid Research, vol. 38, no. 10, pp. 1963-1972, 1997.

[58] J. Ruzickova, M. Rossmeisl, T. Prazak et al., "Omega-3 PUFA of marine origin limit diet-induced obesity in mice by reducing cellularity of adipose tissue," Lipids, vol. 39, no. 12, pp. 1177-1185, 2004.

[59] D. Y. Oh, S. Talukdar, E. J. Bae et al., "GPR120 is an omega-3 fatty acid receptor mediating potent anti-inflammatory and insulinsensitizing effects," Cell, vol. 142, no. 5, pp. 687-698, 2010.

[60] C. Couet, J. Delarue, P. Ritz, J.-M. Antoine, and F. Lamisse, "Effect of dietary fish oil on body fat mass and basal fat oxidation in healthy adults," International Journal of Obesity, vol. 21, no. 8, pp. 637-643, 1997.

[61] T. A. Mori, D. Q. Bao, V. Burke, I. B. Puddey, G. F. Watts, and L. J. Beilin, "Dietary fish as a major component of a weight-loss diet: effect on serum lipids, glucose, and insulin metabolism in overweight hypertensive subjects," The American Journal of Clinical Nutrition, vol. 70, no. 5, pp. 817-825, 1999.

[62] J. D. Buckley and P. R. C. Howe, "Long-chain omega-3 polyunsaturated fatty acids may be beneficial for reducing obesity-a review," Nutrients, vol. 2, no. 12, pp. 1212-1230, 2010.

[63] D. E. Cintra, E. R. Ropelle, J. C. Moraes et al., "Unsaturated fatty acids revert diet-induced hypothalamic inflammation in obesity," PLoS ONE, vol. 7, no. 1, Article ID e30571, 2012.

[64] R. Buettner, K. G. Parhofer, M. Woenckhaus et al., "Defining high-fat-diet rat models: metabolic and molecular effects of different fat types," Journal of Molecular Endocrinology, vol. 36, no. 3, pp. 485-501, 2006.

[65] A. P. Simopoulos, "The importance of the ratio of omega6/omega-3 essential fatty acids," Biomedicine \& Pharmacotherapy, vol. 56, no. 8, pp. 365-379, 2002.

[66] A. P. Simopoulos, "The importance of the omega-6/omega3 fatty acid ratio in cardiovascular disease and other chronic diseases," Experimental Biology and Medicine, vol. 233, no. 6, pp. 674-688, 2008.

[67] L. G. Cleland, M. J. James, M. A. Neumann, M. D’Angelo, and R. A. Gibson, "Linoleate inhibits EPA incorporation from dietary fish-oil supplements in human subjects," The American Journal of Clinical Nutrition, vol. 55, no. 2, pp. 395-399, 1992.

[68] M. J. James, L. G. Cleland, R. A. Gibson, and J. S. Hawkes, "Interaction between fish and vegetable oils in relation to rat leucocyte leukotriene production," The Journal of Nutrition, vol. 121, no. 5, pp. 631-637, 1991.

[69] P. Wortman, Y. Miyazaki, N. S. Kalupahana et al., "n3 and $\mathrm{n} 6$ polyunsaturated fatty acids differentially modulate prostaglandin E secretion but not markers of lipogenesis in adipocytes," Nutrition \& Metabolism, vol. 6, article 5, 2009.

[70] L. M. Arterburn, E. B. Hall, and H. Oken, "Distribution, interconversion, and dose response of n-3 fatty acids in humans," The
American Journal of Clinical Nutrition, vol. 83, no. 6, pp. S14671476S, 2006.

[71] J. T. Brenna, N. Salem Jr., A. J. Sinclair, and S. C. Cunnane, " $\alpha$-linolenic acid supplementation and conversion to n-3 longchain polyunsaturated fatty acids in humans," Prostaglandins Leukotrienes and Essential Fatty Acids, vol. 80, no. 2-3, pp. 85-91, 2009.

[72] P. C. Calder, "Polyunsaturated fatty acids and inflammation," Prostaglandins, Leukotrienes and Essential Fatty Acids, vol. 75, no. 3, pp. 197-202, 2006.

[73] C. C. Tai and S. T. Ding, "N-3 polyunsaturated fatty acids regulate lipid metabolism through several inflammation mediators: mechanisms and implications for obesity prevention," The Journal of Nutritional Biochemistry, vol. 21, no. 5, pp. 357-363, 2010.

[74] N. S. Kalupahana, K. J. Claycombe, and N. Moustaid-Moussa, "(n-3) Fatty acids alleviate adipose tissue inflammation and insulin resistance: mechanistic insights," Advances in Nutrition, vol. 2, no. 4, pp. 304-316, 2011.

[75] M. J. James, R. A. Gibson, and L. G. Cleland, "Dietary polyunsaturated fatty acids and inflammatory mediator production," The American Journal of Clinical Nutrition, vol. 71, no. 1, supplement, pp. 343S-348S, 2000.

[76] T. H. Lee, R. L. Hoover, J. D. Williams et al., "Effect of dietary enrichment with eicosapentaenoic and docosahexaenoic acids on in vitro neutrophil and monocyte leukotriene generation and neutrophil function," The New England Journal of Medicine, vol. 312, no. 19, pp. 1217-1224, 1985.

[77] B. R. Lokesh and J. E. Kinsella, "Modulation of prostaglandin synthesis in mouse peritoneal macrophages by enrichment of lipids with either eicosapentaenoic or docosahexaenoic acids in vitro," Immunobiology, vol. 175, no. 5, pp. 406-419, 1987.

[78] A. Ariel and C. N. Serhan, "Resolvins and protectins in the termination program of acute inflammation," Trends in Immunology, vol. 28, no. 4, pp. 176-183, 2007.

[79] A. González-Périz and J. Clària, "Resolution of adipose tissue inflammation," TheScientificWorldJournal, vol. 10, pp. 832-856, 2010.

[80] D. W. Gilroy, T. Lawrence, M. Perretti, and A. G. Rossi, "Inflammatory resolution: new opportunities for drug discovery," Nature Reviews Drug Discovery, vol. 3, no. 5, pp. 401-416, 2004.

[81] J. M. Schwab, N. Chiang, M. Arita, and C. N. Serhan, "Resolvin E1 and protectin D1 activate inflammation-resolution programmes," Nature, vol. 447, no. 7146, pp. 869-874, 2007.

[82] E. Titos, B. Rius, A. González-Périz et al., "Resolvin D1 and its precursor docosahexaenoic acid promote resolution of adipose tissue inflammation by eliciting macrophage polarization toward an M2-like phenotype," The Journal of Immunology, vol. 187, no. 10, pp. 5408-5418, 2011.

[83] G. E. Caughey, E. Mantzioris, R. A. Gibson, L. G. Cleland, and M. J. James, "The effect on human tumor necrosis factor $\alpha$ and interleukin $1 \beta$ production of diets enriched in n-3 fatty acids from vegetable oil or fish oil," The American Journal of Clinical Nutrition, vol. 63, no. 1, pp. 116-122, 1996.

[84] S. N. Meydani, S. Endres, M. M. Woods et al., "Oral (n-3) fatty acid supplementation suppresses cytokine production and lymphocyte proliferation: comparison between young and older women," Journal of Nutrition, vol. 121, no. 4, pp. 547-555, 1991.

[85] S. Endres, R. Ghorbani, V. E. Kelley et al., "The effect of dietary supplementation with n-3 polyunsaturated fatty acids on the synthesis of interleukin-1 and tumor necrosis factor by 
mononuclear cells," The New England Journal of Medicine, vol. 320, no. 5, pp. 265-271, 1989.

[86] T. E. Novak, T. A. Babcock, D. H. Jho, W. S. Helton, and N. J. Espat, "NF- $\kappa$ B inhibition by $\omega-3$ fatty acids modulates LPSstimulated macrophage TNF- $\alpha$-transcription," The American Journal of Physiology-Lung Cellular and Molecular Physiology, vol. 284, no. 1, pp. L84-L89, 2003.

[87] Y. Zhao, S. Joshi-Barve, S. Barve, and L. H. Chen, "Eicosapentaenoic acid prevents LPS-induced TNF- $\alpha$ expression by preventing NF- $\kappa \mathrm{B}$ activation," Journal of the American College of Nutrition, vol. 23, no. 1, pp. 71-78, 2004.

[88] G. Zhao, T. D. Etherton, K. R. Martin et al., "Anti-inflammatory effects of polyunsaturated fatty acids in THP-1 cells," Biochemical and Biophysical Research Communications, vol. 336, no. 3, pp. 909-917, 2005.

[89] M. Zeyda, D. Farmer, J. Todoric et al., "Human adipose tissue macrophages are of an anti-inflammatory phenotype but capable of excessive pro-inflammatory mediator production," International Journal of Obesity, vol. 31, no. 9, pp. 1420-1428, 2007.

[90] J. Todoric, M. Löffler, J. Huber et al., "Adipose tissue inflammation induced by high-fat diet in obese diabetic mice is prevented by $n-3$ polyunsaturated fatty acids," Diabetologia, vol. 49 , no. 9 , pp. 2109-2119, 2006.

[91] D. A. Raptis, P. Limani, J. H. Jang et al., "GPR120 on Kupffer cells mediates hepatoprotective effects of $\omega 3$-fatty acids," Journal of Hepatology, vol. 60, no. 3, pp. 625-632, 2014.

[92] H.-K. Kim, M. Della-Fera, J. Lin, and C. A. Baile, "Docosahexaenoic acid inhibits adipocyte differentiation and induces apoptosis in 3T3-L1 preadipocytes," The Journal of Nutrition, vol. 136, no. 12, pp. 2965-2969, 2006.

[93] P. Flachs, O. Horakova, P. Brauner et al., "Polyunsaturated fatty acids of marine origin upregulate mitochondrial biogenesis and induce $\beta$-oxidation in white fat," Diabetologia, vol. 48, no. 11, pp. 2365-2375, 2005.

[94] P. Janovská, P. Flachs, L. Kazdová, and J. Kopecký, "Anti-obesity effect of $n$ - 3 polyunsaturated fatty acids in mice fed high-fat diet is independent of cold-induced thermogenesis," Physiological Research, vol. 62, no. 2, pp. 153-161, 2013.

[95] J. Huber, M. Löffler, M. Bilban et al., "Prevention of high-fat diet-induced adipose tissue remodeling in obese diabetic mice by n-3 polyunsaturated fatty acids," International Journal of Obesity, vol. 31, no. 6, pp. 1004-1013, 2007.

[96] A. Okuno, H. Tamemoto, K. Tobe et al., "Troglitazone increases the number of small adipocytes without the change of white adipose tissue mass in obese Zucker rats," The Journal of Clinical Investigation, vol. 101, no. 6, pp. 1354-1361, 1998.

[97] N. S. Kalupahana, K. Claycombe, S. J. Newman et al., "Eicosapentaenoic acid prevents and reverses insulin resistance in high-fat diet-induced obese mice via modulation of adipose tissue inflammation," The Journal of Nutrition, vol. 140, no. 11, pp. 1915-1922, 2010.

[98] A. S. Rossi, Y. B. Lombardo, J.-M. Lacorte et al., "Dietary fish oil positively regulates plasma leptin and adiponectin levels in sucrose-fed, insulin-resistant rats," American Journal of Physiology-Regulatory Integrative and Comparative Physiology, vol. 289, no. 2, pp. R486-R494, 2005.

[99] C. Fan, X. Liu, W. Shen, R. J. Deckelbaum, and K. Qi, “The regulation of leptin, leptin receptor and pro-opiomelanocortin expression by N-3 PUFAs in diet-induced obese mice is not related to the methylation of their promoters," Nutrition \& Metabolism, vol. 8, article 31, 2011.
[100] P. Flachs, V. Mohamed-Ali, O. Horakova et al., "Polyunsaturated fatty acids of marine origin induce adiponectin in mice fed a high-fat diet," Diabetologia, vol. 49, no. 2, pp. 394-397, 2006.

[101] N. Pérez-Echarri, P. Pérez-Matute, B. Marcos-Gómez, J. A. Martínez, and M. J. Moreno-Aliaga, "Effects of eicosapentaenoic acid ethyl ester on visfatin and apelin in lean and overweight (cafeteria diet-fed) rats," British Journal of Nutrition, vol. 101, no. 7, pp. 1059-1067, 2009.

[102] M. Muurling, R. P. Mensink, H. Pijl, J. A. Romijn, L. M. Havekes, and P. J. Voshol, "A fish oil diet does not reverse insulin resistance despite decreased adipose tissue TNF- $\alpha$ protein concentration in ApoE- $3^{*}$ leiden mice," Journal of Nutrition, vol. 133, no. 11, pp. 3350-3355, 2003.

[103] N. Pérez-Echarri, P. Pérez-Matute, B. Marcos-Gómez et al., "Differential inflammatory status in rats susceptible or resistant to diet-induced obesity: effects of EPA ethyl ester treatment," European Journal of Nutrition, vol. 47, no. 7, pp. 380-386, 2008.

[104] J. Luo, S. W. Rizkalla, J. Boillot et al., "Dietary (n-3) polyunsaturated fatty acids improve adipocyte insulin action and glucose metabolism in insulin-resistant rats: relation to membrane fatty acids," The Journal of Nutrition, vol. 126, no. 8, pp. 1951-1958, 1996.

[105] M. Fickova, P. Hubert, G. Crémel, and C. Leray, "Dietary (n-3) and (n-6) polyunsaturated fatty acids rapidly modify fatty acid composition and insulin effects in rat adipocytes," The Journal of Nutrition, vol. 128, no. 3, pp. 512-519, 1998.

[106] G. R. Herzberg and C. Skinner, "Differential accumulation and release of long-chain n-3 fatty acids from liver, muscle, and adipose tissue triacylglycerols," Canadian Journal of Physiology and Pharmacology, vol. 75, no. 8, pp. 945-951, 1997.

[107] J. D. Krebs, L. M. Browning, N. K. McLean et al., "Additive benefits of long-chain n-3 polyunsaturated fatty acids and weight-loss in the management of cardiovascular disease risk in overweight hyperinsulinaemic women," International Journal of Obesity, vol. 30, no. 10, pp. 1535-1544, 2006.

[108] Y. B. Lombardo, G. Hein, and A. Chicco, "Metabolic syndrome: effects of n-3 PUFAs on a model of dyslipidemia, insulin resistance and adiposity," Lipids, vol. 42, no. 5, pp. 427-437, 2007.

[109] A. Haug and A. T. Høstmark, "Lipoprotein lipases, lipoproteins and tissue lipids in rats fed fish oil or coconut oil," Journal of Nutrition, vol. 117, no. 6, pp. 1011-1017, 1987.

[110] T. Yamauchi, J. Kamon, Y. Minokoshi et al., "Adiponectin stimulates glucose utilization and fatty-acid oxidation by activating AMP-activated protein kinase," Nature Medicine, vol. 8, no. 11, pp. 1288-1295, 2002.

[111] Y. Sharabi, M. Oron-Herman, Y. Kamari et al., "Effect of PPAR$\gamma$ agonist on adiponectin levels in the metabolic syndrome: lessons from the high fructose fed rat model," American Journal of Hypertension, vol. 20, no. 2, pp. 206-210, 2007.

[112] M. Iwabu, T. Yamauchi, M. Okada-Iwabu et al., "Adiponectin and AdipoR1 regulate PGC- $1 \alpha$ and mitochondria by $\mathrm{Ca}^{2+}$ and AMPK/SIRT1," Nature, vol. 464, no. 7293, pp. 1313-1319, 2010.

[113] X. Zhang, G. Zhang, H. Zhang, M. Karin, H. Bai, and D. Cai, "Hypothalamic IKK $\beta / \mathrm{NF}-\kappa \mathrm{B}$ and ER stress link overnutrition to energy imbalance and obesity," Cell, vol. 135, no. 1, pp. 61-73, 2008.

[114] M. Milanski, G. Degasperi, A. Coope et al., "Saturated fatty acids produce an inflammatory response predominantly through the activation of TLR4 signaling in hypothalamus: implications for the pathogenesis of obesity," The Journal of Neuroscience, vol. 29, no. 2, pp. 359-370, 2009. 
[115] L. A. Moraes, L. Piqueras, and D. Bishop-Bailey, "Peroxisome proliferator-activated receptors and inflammation," Pharmacology \& Therapeutics, vol. 110, no. 3, pp. 371-385, 2006.

[116] F. Huang, H. Wei, H. Luo, S. Jiang, and J. Peng, "EPA inhibits the inhibitor of $\kappa \mathrm{b} \alpha(\mathrm{I} \kappa \mathrm{B} \alpha) / \mathrm{NF}-\kappa \mathrm{B} /$ muscle RING finger 1 pathway in $\mathrm{C} 2 \mathrm{C} 12$ myotubes in a PPAR $\gamma$-dependent manner," British Journal of Nutrition, vol. 105, no. 3, pp. 348-356, 2011.

[117] M. Ricote, A. C. Li, T. M. Willson, C. J. Kelly, and C. K. Glass, "The peroxisome proliferator-activated receptor- $\gamma$ is a negative regulator of macrophage activation," Nature, vol. 391, no. 6662, pp. 79-82, 1998.

[118] J. Zúñiga, M. Cancino, F. Medina et al., "N-3 PUFA supplementation triggers PPAR- $\alpha$ activation and PPAR- $\alpha / N F-\kappa B$ interaction: anti-inflammatory implications in liver ischemiareperfusion injury," PLoS ONE, vol. 6, no. 12, Article ID e28502, 2011.

[119] J. Kopecky, M. Rossmeisl, P. Flachs et al., "N-3 PUFA: bioavailability and modulation of adipose tissue function," Proceedings of the Nutrition Society, vol. 68, no. 4, pp. 361-369, 2009.

[120] T. Obata, T. Nagakura, T. Masaki, K. Maekawa, and K. Yamashita, "Eicosapentaenoic acid inhibits prostaglandin D2 generation by inhibiting cyclo-oxygenase- 2 in cultured human mast cells," Clinical \& Experimental Allergy, vol. 29, no. 8, pp. 1129-1135, 1999.

[121] P. Yaqoob and S. R. Shaikh, "The nutritional and clinical significance of lipid rafts," Current Opinion in Clinical Nutrition \& Metabolic Care, vol. 13, no. 2, pp. 156-166, 2010.

[122] T. M. Stulnig, J. Huber, N. Leitinger et al., "Polyunsaturated eicosapentaenoic acid displaces proteins from membrane rafts by altering raft lipid composition," Journal of Biological Chemistry, vol. 276, no. 40, pp. 37335-37340, 2001.

[123] Q. Li, M. Wang, L. Tan et al., "Docosahexaenoic acid changes lipid composition and interleukin-2 receptor signaling in membrane rafts," The Journal of Lipid Research, vol. 46, no. 9, pp. 1904-1913, 2005.

[124] L. Villacorta, L. Chang, S. R. Salvatore et al., "Electrophilic nitro-fatty acids inhibit vascular inflammation by disrupting LPS-dependent TLR4 signalling in lipid rafts," Cardiovascular Research, vol. 98, no. 1, pp. 116-124, 2013.

[125] P. R. Devchand, H. Keller, J. M. Peters, M. Vazquez, F. J. Gonzalez, and W. Wahli, "The PPAR $\alpha$-leukotriene $\mathrm{B}_{4}$ pathway to inflammation control," Nature, vol. 384, no. 6604, pp. 39-43, 1996.

[126] R. Kapadia, J.-H. Yi, and R. Vemuganti, "Mechanisms of antiinflammatory and neuroprotective actions of PPAR-gamma agonists," Frontiers in Bioscience, vol. 13, no. 5, pp. 1813-1826, 2008.

[127] A. Chawla, E. J. Schwarz, D. D. Dimaculangan, and M. A. Lazar, "Peroxisome proliferator-activated receptor (PPAR) $\gamma$ : adiposepredominant expression and induction early in adipocyte differentiation," Endocrinology, vol. 135, no. 2, pp. 798-800, 1994.

[128] B. M. Spiegelman, "PPAR- $\gamma$ : adipogenic regulator and thiazolidinedione receptor," Diabetes, vol. 47, no. 4, pp. 507-514, 1998.

[129] P. Tontonoz, E. Hu, and B. M. Spiegelman, "Stimulation of adipogenesis in fibroblasts by PPAR $\gamma 2$, a lipid-activated transcription factor," Cell, vol. 79, no. 7, pp. 1147-1156, 1994.

[130] X. Yang and U. Smith, "Adipose tissue distribution and risk of metabolic disease: does thiazolidinedione-induced adipose tissue redistribution provide a clue to the answer?" Diabetologia, vol. 50, no. 6, pp. 1127-1139, 2007.
[131] L. Tao, Y. Wang, E. Gao et al., "Adiponectin: an indispensable molecule in rosiglitazone cardioprotection following myocardial infarction," Circulation Research, vol.106, no. 2, pp. 409-417, 2010.

[132] J. M. Tishinsky, D. W. L. Ma, and L. E. Robinson, "Eicosapentaenoic acid and rosiglitazone increase adiponectin in an additive and PPAR $\gamma$-dependent manner in human adipocytes," Obesity, vol. 19, no. 2, pp. 262-268, 2011.

[133] S. Neschen, K. Morino, J. C. Rossbacher et al., "Fish oil regulates adiponectin secretion by a peroxisome proliferator-activated receptor- $\gamma$-dependent mechanism in mice," Diabetes, vol. 55, no. 4, pp. 924-928, 2006.

[134] R. Stienstra, C. Duval, S. Keshtkar, J. van der Laak, S. Kersten, and M. Müller, "Peroxisome proliferator-activated receptor $\gamma$ activation promotes infiltration of alternatively activated macrophages into adipose tissue," The Journal of Biological Chemistry, vol. 283, no. 33, pp. 22620-22627, 2008.

[135] J. I. Odegaard, R. R. Ricardo-Gonzalez, M. H. Goforth et al., "Macrophage-specific PPAR $\gamma$ controls alternative activation and improves insulin resistance," Nature, vol. 447, no. 7148, pp. 1116-1120, 2007.

[136] A. L. Hevener, J. M. Olefsky, D. Reichart et al., "Macrophage PPAR $\gamma$ is required for normal skeletal muscle and hepatic insulin sensitivity and full antidiabetic effects of thiazolidinediones," The Journal of Clinical Investigation, vol. 117, no. 6, pp. 1658-1669, 2007.

[137] C. Jiang, A. T. Ting, and B. Seed, "PPAR- $\gamma$ agonists inhibit production of monocyte inflammatory cytokines," Nature, vol. 391, no. 6662, pp. 82-86, 1998.

[138] D. Cipolletta, M. Feuerer, A. Li et al., "PPAR- $\gamma$ is a major driver of the accumulation and phenotype of adipose tissue $\mathrm{T}_{\text {reg }}$ cells," Nature, vol. 486, no. 7404, pp. 549-553, 2012.

[139] G. Krey, O. Braissant, F. L'Horset et al., "Fatty acids, eicosanoids, and hypolipidemic agents identified as ligands of peroxisome proliferator-activated receptors by coactivator-dependent receptor ligand assay," Molecular Endocrinology, vol. 11, no. 6, pp. 779-791, 1997.

[140] E. Oliver, F. McGillicuddy, C. Phillips, S. Toomey, and H. M. Roche, "The role of inflammation and macrophage accumulation in the development of obesity-induced type 2 diabetes mellitus and the possible therapeutic effects of long-chain n-3 PUFA," Proceedings of the Nutrition Society, vol. 69, no. 2, pp. 232-243, 2010.

[141] R. G. Baker, M. S. Hayden, and S. Ghosh, "NF- $\kappa$ B, inflammation, and metabolic disease," Cell Metabolism, vol. 13, no. 1, pp. 11-22, 2011.

[142] D. Cai, M. Yuan, D. F. Frantz et al., "Local and systemic insulin resistance resulting from hepatic activation of IKK- $\beta$ and NF$\kappa$ B," Nature Medicine, vol. 11, no. 2, pp. 183-190, 2005.

[143] M. C. Arkan, A. L. Hevener, F. R. Greten et al., "IKK- $\beta$ links inflammation to obesity-induced insulin resistance," Nature Medicine, vol. 11, no. 2, pp. 191-198, 2005.

[144] F. R. Greten, L. Eckmann, T. F. Greten et al., "IKK $\beta$ links inflammation and tumorigenesis in a mouse model of colitisassociated cancer," Cell, vol. 118, no. 3, pp. 285-296, 2004.

[145] Y. Wang, Q.-W. Lin, P.-P. Zheng, J.-S. Zhang, and F.-R. Huang, "DHA inhibits protein degradation more efficiently than EPA by regulating the PPAR $\gamma / \mathrm{NF} \kappa \mathrm{B}$ pathway in $\mathrm{C} 2 \mathrm{C} 12$ myotubes," BioMed Research International, vol. 2013, Article ID 318981, 9 pages, 2013.

[146] J. Y. Lee, K. H. Sohn, S. H. Rhee, and D. Hwang, "Saturated fatty acids, but not unsaturated fatty acids, induce the expression of 
cyclooxygenase-2 mediated through Toll-like receptor 4," The Journal of Biological Chemistry, vol. 276, no. 20, pp. 1668316689, 2001.

[147] A. Hirasawa, K. Tsumaya, T. Awaji et al., "Free fatty acids regulate gut incretin glucagon-like peptide-1 secretion through GPR120," Nature Medicine, vol. 11, no. 1, pp. 90-94, 2005.

[148] A. Ichimura, A. Hirasawa, O. Poulain-Godefroy et al., "Dysfunction of lipid sensor GPR120 leads to obesity in both mouse and human," Nature, vol. 483, no. 7389, pp. 350-354, 2012.

[149] J. C. Jiménez-Chillarón, R. Díaz, D. Martínez et al., “The role of nutrition on epigenetic modifications and their implications on health," Biochimie, vol. 94, no. 11, pp. 2242-2263, 2012.

[150] N. A. Youngson and M. J. Morris, "What obesity research tells us about epigenetic mechanisms," Philosophical Transactions of the Royal Society B: Biological Sciences, vol. 368, no. 1609, 2013.

[151] V. Ceccarelli, S. Racanicchi, M. P. Martelli et al., "Eicosapentaenoic acid demethylates a single $\mathrm{CpG}$ that mediates expression of tumor suppressor CCAAT/enhancer-binding protein $\delta$ in U937 leukemia cells," The Journal of Biological Chemistry, vol. 286, no. 31, pp. 27092-27102, 2011.

[152] V. Primeau, L. Coderre, A. D. Karelis et al., "Characterizing the profile of obese patients who are metabolically healthy," International Journal of Obesity, vol. 35, no. 7, pp. 971-981, 2011. 

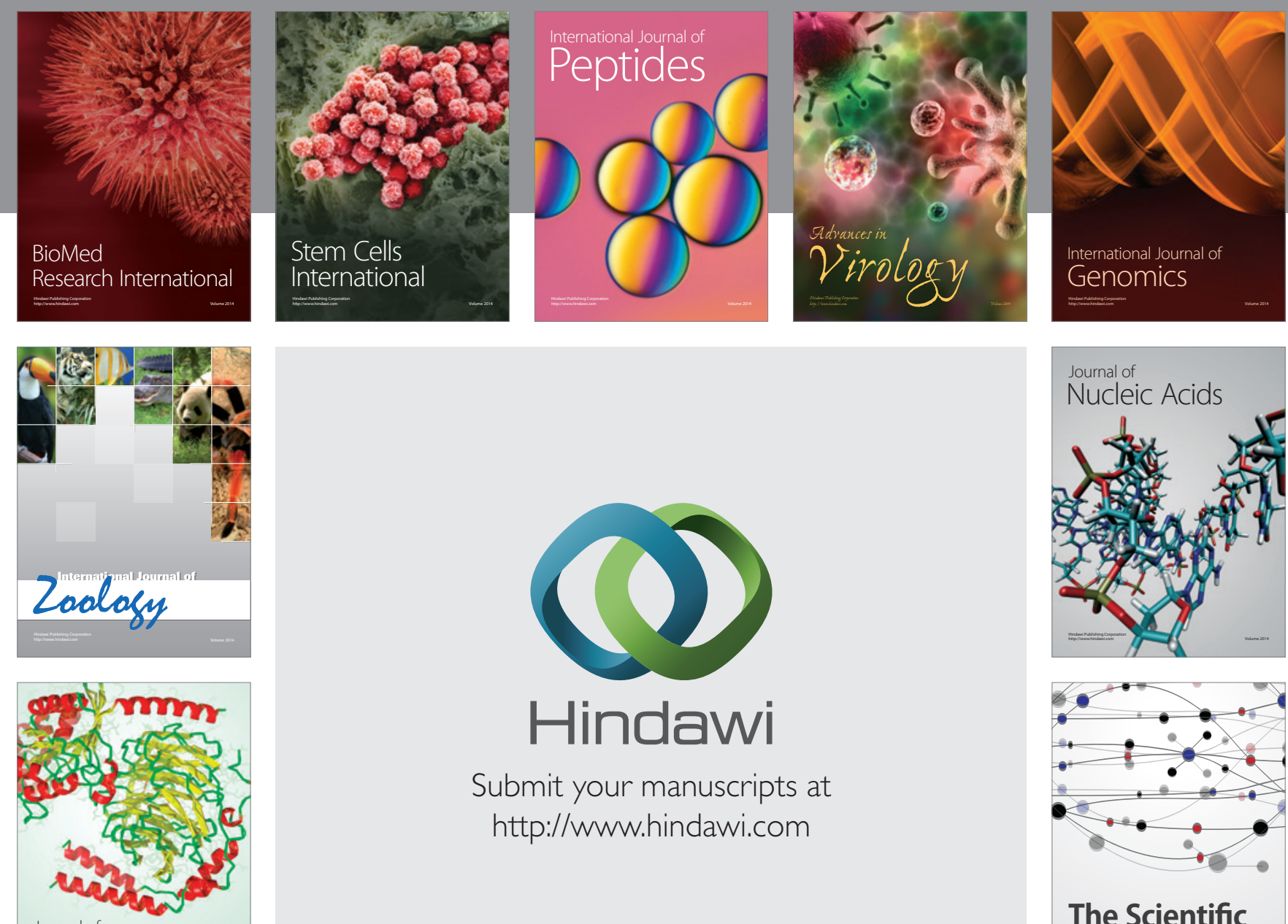

Submit your manuscripts at

http://www.hindawi.com

Journal of
Signal Transduction
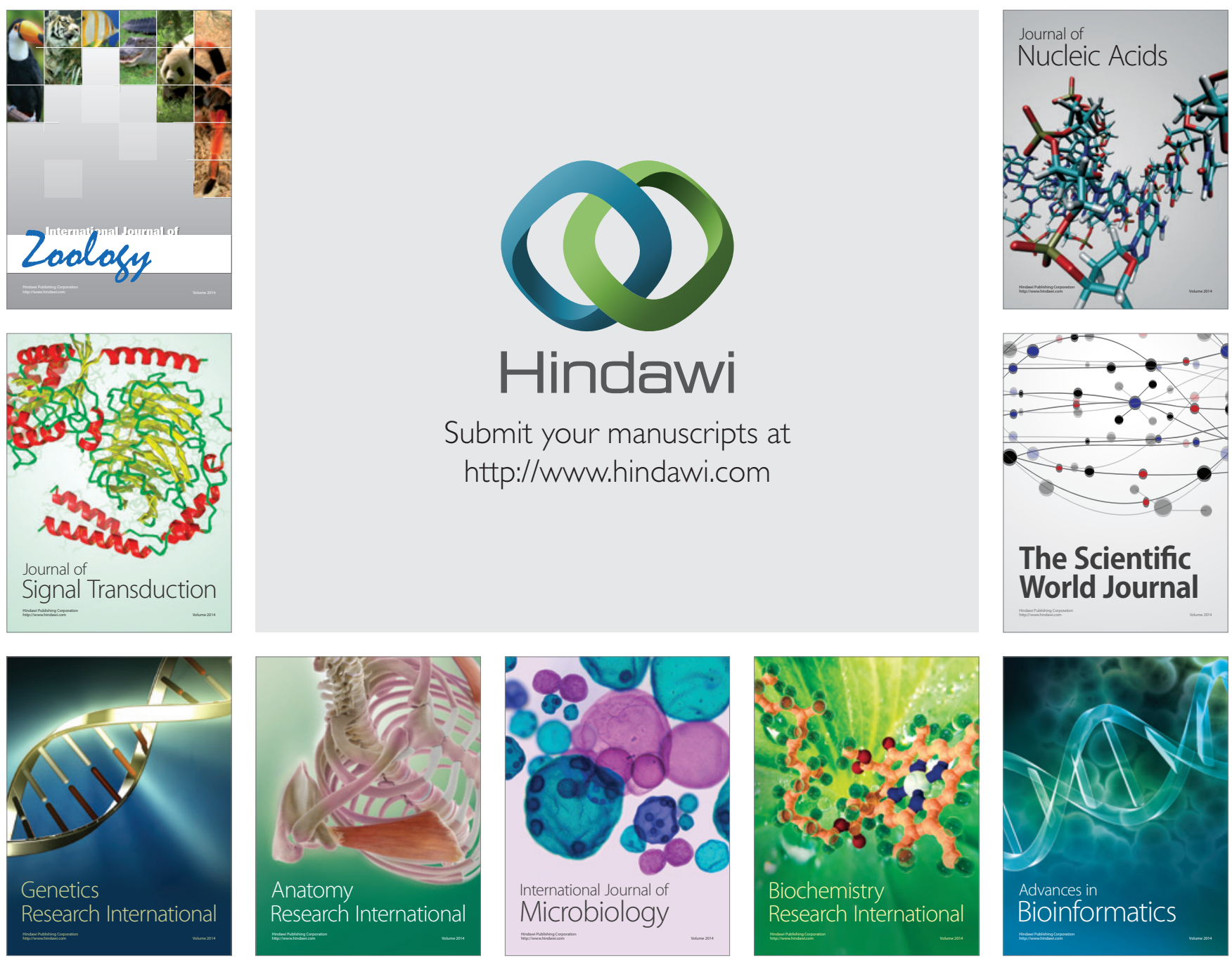

The Scientific World Journal
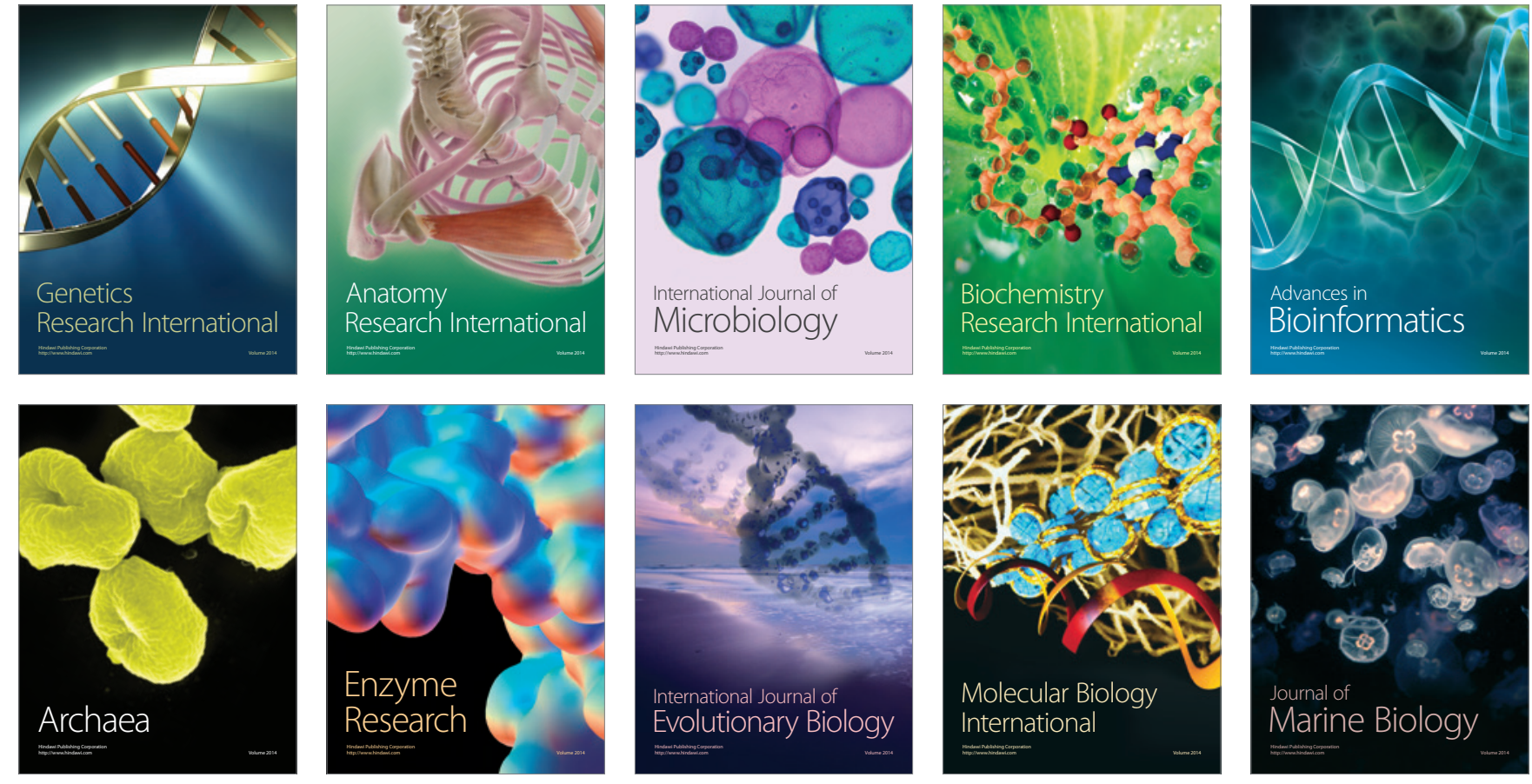